Alma Mater Studiorum - Università di Bologna DEPARTMENT OF ECONOMICS

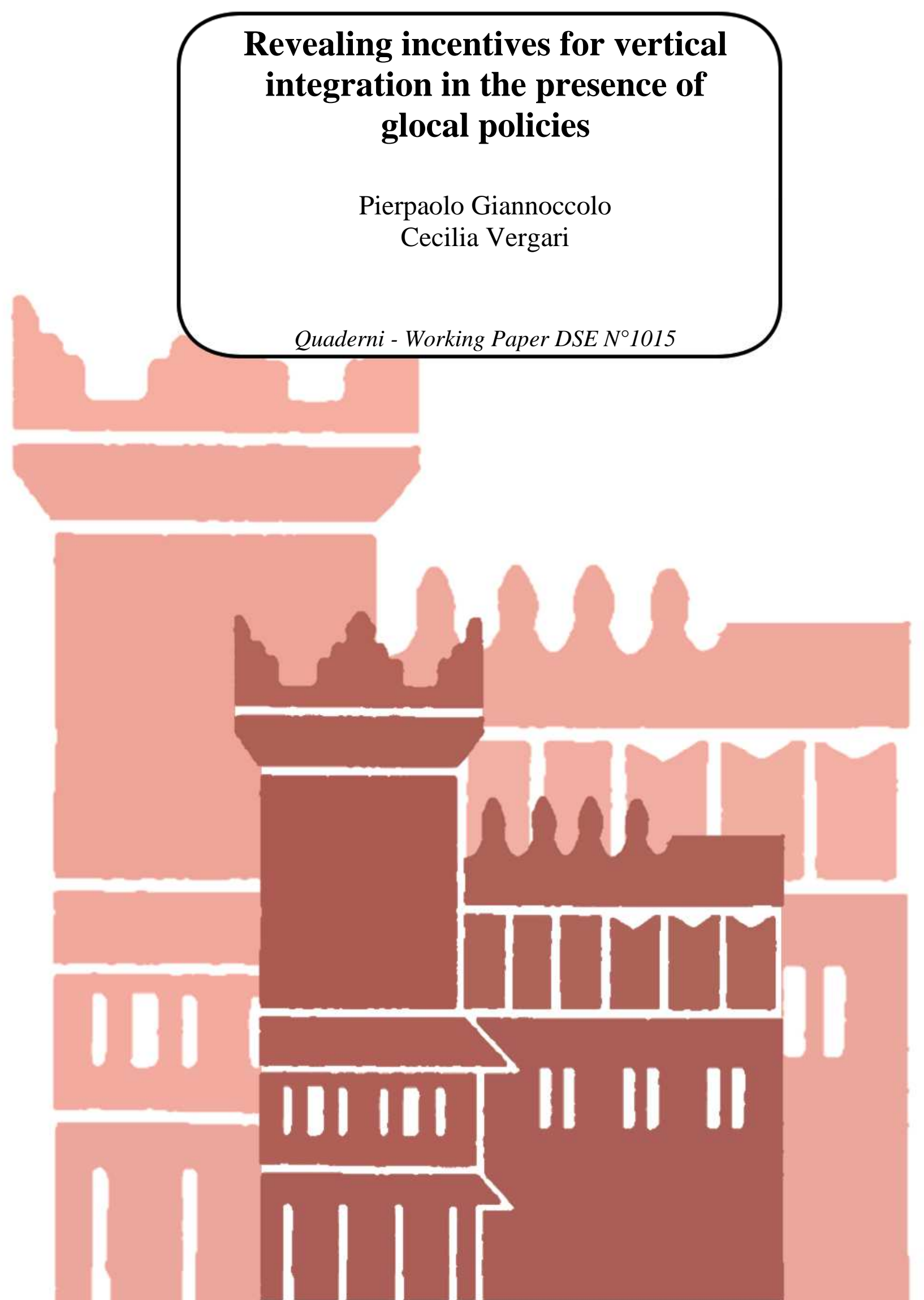




\title{
Revealing incentives for vertical integration in the presence of glocal policies*
}

\author{
Pierpaolo Giannoccolo ${ }^{\dagger} \quad$ Cecilia Vergari ${ }^{\ddagger}$
}

June 18, 2015

\begin{abstract}
Local and regional policy makers are acquiring an increasingly active role in affecting firms' specialization decisions that in turn influence firms' vertical organization. We analyse the relation between vertical integration incentives and trade liberalization in the presence of glocal policies, i.e., specific (local) policies that have international (global) impact.

More precisely, one of the most important reasons for vertical integration in the presence of sunk costs of specialization is avoiding the risk of hold up. We introduce the idea that this sunk cost can be manipulated by the policy maker at national/regional/local level. We characterize the conditions under which policies are effective in achieving a particular equilibrium in terms of vertical structure and specialization decision. The main result is that the policy effectiveness is stronger the higher is the importance of the hold-up problem. In particular, we investigate how glocal policies interact with policies that affect the market openness (trade policy). We find that for high values of the specialization upgrade cost, trade policies are ineffective. At the same time, if the trading cost is very low, glocal policies are ineffective. Finally, in the presence of intermediate specialization upgrade and trading cost, either policy supplements the other policy.
\end{abstract}

JEL classification: D23, F15, F23, H54, L22.

Keywords: Input production, vertical integration, hold-up problem, glocal policies, international openness.

\footnotetext{
${ }^{*}$ We thank for useful comments on a previous version Oscar Amerighi, Luigi Filippini and Marco Grazzi. We acknowledge the financial support of the Fondazione Cassa di Risparmio Forlì.

${ }^{\dagger}$ Department of Economics (University of Bologna) pierpaolo.giannoccolo@unibo.it

${ }^{\ddagger}$ Department of Economics (University of Bologna) cecilia.vergari@unibo.it.
} 


\section{Introduction}

There is a growing literature studying the role of trade liberalization on industry vertical structure. The main mechanism being the effect of international openness on opportunism problems generated by hold-up. The pioneering contribution is McLaren (2000). He shows that openness affects firms' decision to produce either a specialized or flexible input and in turn whether to vertically integrate, by mitigating the unbalanced bargaining power. More precisely, the production of a specialized input requires sunk cost that gives to the buyer a kind of monopsony power. In particular, in the absence of alternative buyers, the risk for the input producer of not recouping its cost ex post generates hold up. In McLaren trade liberalization mitigates this problem by rising the market thickness, that is increasing the number of alternative buyers (i.e. the foreign firms).

We argue that in the framework of vertical integration decisions and trade liberalization a new actor is acquiring an increasingly active role: local and regional policy makers. More precisely, we analyse the relation between vertical integration incentives and trade liberalization in the presence of glocal policies, i.e., specific local policies that have global impact. Namely, we refer to the neologism "glocalization" described in the Think Tank on Glocalization held in Rome (May 2003) that aims to integrate the strong powers of global governance and the strenght of the local dimension. In line with their approach, we want to emphasize the fact that the global effect of a policy is more likely to succeed when this policy is adapted specifically to each locality or culture and to "establish a link between the benefits of the global dimension and the local realities, while at the same time, establishing a bottom up system for the governance of globalization" (Glocal Forum 2003, p. 13-14). ${ }^{1}$ We focus on glocal policies that affect firms' vertical organization by mitigating the hold-up problem. A recent example can be found in Emilia-Romagna (Italy). On March 4, 2013 the University of Bologna jointly with Unindustria Bologna created AlmaCube Limited Company. ${ }^{2}$ This is an innovative way to prompt the creation of start-up. Indeed, for the first time in Italy, institutional sponsors not only give financial, administrative and fiscal facilities to new start-up but become partners by taking a relevant part of the entrepreneurial risk. In this way the sunk cost of producing an innovative and specialized input is shared between the private and public partners. Consequently the risk of hold-up for the private entrepreneur is mitigated. At European level we can find other examples in the Horizon 2020 program, ${ }^{3}$ like the initiatives devoted to small and medium enterprises (SMEs), in particular "providing support to help single SMEs, or consortia of SMEs, assess the market viability of their ideas at the high-risk stage, and then to help them develop these ideas further." ${ }^{4}$ Further

\footnotetext{
${ }^{1}$ The relevance of these policies is analysed by several scholars. Martins and Rodrigiez Alvarez (2007) emphasize the growning role of local leaders in a global context; Iammarino and Santangelo (2000) analyse the attractiveness of the Italian regions for FDI; Isaksen and Onsager (2010) study the knowledge-intensive industries in Norway and find that the small urban regions and the rural regions have a higher share of innovating, knowledge-intensive firms than the large urban regions, which may partly be explained by a much higher rate of public funding of innovation activity in the first two regional types.

${ }^{2}$ See http://www.almacube.com.

${ }^{3}$ Further examples are in Section 5.

${ }^{4}$ See http://ec.europa.eu/programmes/horizon2020/sites/horizon2020/files/H2020_inBrief_EN_FinalBAT.pdf, page 10 .
} 
motivation for our analysis comes from the increasing demand for such specific policies. An example is provided by Ducati and Lamborghini's recent proposal for Emilia Romagna high school students to do a two years internship. In September 2014 these two Volkswagen group's firms have signed a joint agreement with the Unions, the local Institutions and the Ministry of Education. ${ }^{5}$ Our aim is to investigate the effect of the interaction between these policies and international openness on firms' vertical organization.

The main ingredients of our model are the following ones. We consider a competitive market with a number of output and input producers. Each final output needs an essential input produced by an upstream firm. An input can be either (fully) specialized for a specific final good or flexible that is suitable for any final good production. The specialized input confers a higher value to the output for which it has been designed than the flexible input but it implies higher sunk costs of production and in turn higher risk for the input producer to be held-up. In the literature, different degrees of specialization have been introduced. For instance, while McLaren (2000) focuses on the extreme case of full specialization, Grossman and Helpman (2002) introduce the idea that specialization typically occurs in stages so that for each final good there is an ideal component, but final producers can use less specialized components at additional costs. In line with this literature, we consider different degrees of specialization that imply different degrees of hold-up (i.e. probability to recoup the sunk cost of input production). Namely, in the full specialization case, the input is perfectly suitable for only one final good, in other words the input is so specialized that only one downstream firm can use it (one upstream firm for one downstream firm); lower degrees of specialization mean that the features of the input are such that it can be adapted to at least two final goods (one upstream firm for more than one downstream firm). Intuitively, given the dynamic path of the technologies, it may well happen that, at a certain point of this path, two downstream firms use the same specialized input (for instance they could have invested in the same basic research, as a joint venture or as sponsors and beneficiaries of the same public research institute). In the latter case, even though our less specialized input could somewhat resemble a flexible input, this is not the case: this input is always specialized given that it could be adapted only to a subset of firms. Our definition of specialization recall the flexible manufacturing systems studied by Norman and Thisse (1999). In particular, flexible manufacturing systems (FMS) are defined as "a production unit capable of producing a range of discrete products with a minimum of manual intervention". As they state: "The essence of FMS is that it allows firms to customize their products to the requirements of heterogeneous consumers at little or no cost" ${ }^{6}$

\footnotetext{
${ }^{5} \mathrm{~A}$ similar example is the Bosh pilot working students project in Puglia, for details see for instance the Italian link http://www.lagazzettadelmezzogiorno.it/homepage/ministro-giannini-a-bosch-modugno-no784230.

${ }^{6}$ Norman and Thisse (1999) point out several examples like Hitachi and Mitsubishi in the production of elevators and heavy construction equipment or the Italian ceramic tile manufacturer Marazzi.

Furthermore, in the aircraft industry, the jet (turboprop) engine and the jet (turboprop) aircraft industries are vertically related. To produce a differentiated product, aircraft firms have to procure suitable equipment. Bonaccorsi and Giuri (2001) point out that "in the presence of economies of scope, engine programs are potentially applicable to different aircraft programs of different manufactures. This allows engine companies to relate to many buyers, and potentially to all of them". Furthermore, in the automobile industry, Toyota procures electric parts from Denso, which is one of the largest auto-part manufactures. Denso sometimes supplies to other automobile manufacturers, for instance, Daimler Chrysler. Thus, electric parts may be used in automobiles of different manufactures (Ahmadjian and Lincoln,
} 
More precisely, we assume that different degrees of specialization imply different sunk costs and we introduce the idea that the sunk cost can be manipulated by the policy maker (at national/regional/local level). We show that the equilibria, in terms of vertical structure and specialization decision, depend on the specialization costs (generated by the sunk cost), the integration costs and the trade costs (generated by the international openness): the manipulation of the specialization cost reflects mainly the glocal policies, whereas the manipulation of the integration and trade costs reflect policies at national and international level.

Our main results are as follows. We confirm the results gathered in the literature about the hold up motive for vertical integration, the importance of the outside options for the risk of being held-up and in turn the importance of the market's characteristics (like international openness and asymmetry between buyers and sellers that affect the thickness of the market). Our new results focus on the effects of the interaction between policies at local, regional, national and international level. Namely, in the closed economy (low international openness), the degree of specialization of the inputs and the cost of this specialization are crucial in order to implement policies that influence the firms/clusters' decisions. A higher specialization upgrade cost implies a higher sunk cost and in turn a higher risk of being held up (and vice versa). The manipulation of the specialization upgrade cost is thus effective in influencing firms' vertical structure as long as the inputs are sufficiently specialized. This scenario changes when the trade costs decrease (higher international openness): here, the presence of highly specialized inputs becomes less and less crucial to ensure the effectiveness of manipulating the specialization upgrade costs. Finally, in the absence of trade costs a policy maker is not able anymore to influence the vertical structure of the firms/clusters through such glocal policies. In other terms, manipulating the specialization upgrade cost is always effective (both in the closed and in the open economy) in affecting firms' specialization decision (specialized versus flexible input). However, this policy influences firms' vertical structure only as long as the inputs are highly specialized and the trade barriers are sufficiently high. Indeed, when the inputs are not very specialized as well as the trade barriers are low, the hold-up risk is not significant (as for firms there will always be some alternative buyer, in other words the market is sufficiently thick).

Related literature. Our paper is related to the literature that analyses how firms' boundary choices are affected by market conditions. The theoretical contributions show that the relationship between trade liberalization and industry vertical structure is ambiguous. Our analysis is based on McLaren (2000)'s model, that is a simple still exhaustive framework where the relationship between internationalization and hold-up is clearly defined and we extend this model in several ways. McLaren (2000) focuses on the role of input market thickness that is a result of globalization. In McLaren's words a rise in market thickness can be defined "as any increase in the effective number of firms in a given market, in the sense that there is an increase in the probability that any given agent will be able to find in a given length of time an agent with whom it will be possible to realize gains from trade" (McLaren 2003, p-328). He argues three (new) consequences of the vertical integration decision 2001). 
related to globalization: first, each upstream firm is more likely to find an alternative interested buyer, the more unintegrated firms there are (as the weaker the hold-up problem will be). This is a strategiccomplements property. Second, opening the economy will make it easier for an input supplier to find an attractive alternative buyer abroad. In this sense, international trade can decrease the incentive to vertical integration. Third, openness gives each firm more options in its procurement strategy, and so it is unambiguously efficiency enhancing. McLaren (2000) finds an exact correspondence between ownership structure and technology choice. Moreover, multiple equilibria arise: there is always one equilibrium where all firms are vertically integrated, but if there is a sufficiently high number of firms in the market (as in case of international openness) there is a second equilibrium where all firms are vertically separated. This latter equilibrium is more efficient because it allows to save "the governance costs of running a more complex organization". We depart from McLaren (2000) in what we introduce asymmetry between upstream and downstream firms, different degrees of specialization as well as the possibility for the policy maker to affect the specialization cost and in turn firms' vertical organization. The presence of this asymmetry and intermediate degrees of specialization alleviates the hold-up problem and in turn it reduces the market thickness effects related to opening the market on firms' organization. We thus have equilibria in which firms with different vertical organizations coexist and there may not be a perfect correspondence between firms' vertical structure and specialization decision. The policy implication is that it is always possible to affect firms' specialization decision, however as the market becomes thicker it may not be possible to influence firms' vertical structure.

Grossman and Helpman (2002) develop a more complex framework and study the determinants of the firms' equilibrium vertical organization when inputs are fully or partially specialized. ${ }^{7}$ Similarly to McLaren, they find that as the number of firms on each side of the market grows, there can be two stable equilibria: one with vertical integration and the other with outsourcing. Outsourcing is more likely to be viable in large industries / economies because of the advantage of a thicker market. ${ }^{8}$ So that, in line with McLaren, they find that an industry is unlikely to be populated by firms with different organizational forms basically because they assume that all potential entrants are of the same type.

In the previous contributions, as in our model, competition effects are absent. In contrast, Wes (2000) develops a bilateral monopoly model and point out a pro-competitive effect in the output market associated with international trade that also alleviates the hold-up problem and thus discourages mergers. Namely, an upstream producer, prior to production, has to make a transaction-specific investment, characterized by increasing returns, to trade with the downstream firm. Wes shows that under autarky there is a holdup problem and the upstream firm underinvests. ${ }^{9}$ International trade between two (identical) countries implies both allocative and productive efficiency gains. Indeed,

\footnotetext{
${ }^{7}$ They consider a general equilibrium model thus accounting for the mechanisms by which a firm's choices affect market conditions, that in turn affect other firms' organization decisions.

${ }^{8}$ However in Grossman and Helpman (2002) the reason for this result is the presence of increasing returns to search, whereas in McLaren "market thickness acts as a brake on opportunism", McLaren (2003), p. 331.

${ }^{9}$ In our model the under-investment is captured by the decision to produce a flexible input.
} 
in the open economy the industrial structure changes from a monopoly to a duopoly so that the price charged by the downstream firm in each country decreases; this increase in product demand in turn raises productive efficiency because it motivates the upstream firms to invest more, given their increasing returns technologies.

Ornelas and Turner (2008) develop a theoretical partial equilibrium model and argue that trade liberalization increases the incentives of foreign suppliers to undertake cost-reducing investments and, in contrast with the previous papers, it may prompt vertical multinational integration. The reason is that in Ornelas and Turner's model the foreign supplier is fully specialized to the home buyer's needs, so its outside option is unaffected by trade liberalization. This effectively shuts down all marketthickening forces. Also, expected trade volumes are larger when firms are integrated, accordingly the direct cost of a tariff is higher when the firms are vertically integrated than when they operate under the arm's length arrangement. Then, lower trade costs do not necessarily lead to more outsourcing versus vertical integration. Their results relate to the literature on whether trade and FDI are substitutes or complements. On one hand, lower tariffs reduce incentives for vertical integration by mitigating the hold-up problem, implying substitutability. On the other hand, lower tariffs make integration more attractive because of the trade volume effect, implying complementarity. ${ }^{10}$

Conconi et al. (2012) examine how the liberalization of product and factor markets affects firms' integration decisions via the induced changes in (output and input) prices. They develop a perfectlycompetitive, specific-factor model of trade and focus on the trade-off between the managerial "quiet life" (pushing towards the non-integration decision) and the coordination of the production activities (pushing towards integration). They show that, even when firms do not relocate across countries, the price changes triggered by the increase in factor mobility can change the ownership structures within countries. ${ }^{11}$ Similarly, we show that even if input trade does not take place at equilibrium, the price changes triggered by the international openness affect firms' vertical organization.

As for the empirical contributions, there is a vast literature that examines the determinants of firms' vertical integration decisions.

Chongvilaivan and Hur (2012) investigate the effects of trade openness on the pattern of vertical integration using U.S. manufacturing industry data from 2002 to 2006 . Their empirical results reveal

\footnotetext{
${ }^{10}$ Antras (2003) addresses the question of why intra-firm trade is positively correlated with capital-labor ratios across U.S. industries and capital-labor ratios across countries from which the U.S. imports. He develops a property rights model of the boundaries of the firm, in which, in equilibrium transaction costs of using the market are increasing in the capital intensity of the imported good. The attractiveness of vertical integration is shown to be increasing in the capital intensity of intermediate goods production. The argument is based on the idea that investments related to labor input are harder to share than investments in physical capital.

${ }^{11}$ Alfaro et al. (2014) focus on the effect of prices on vertical integration decisions. They test the theoretical statement that integration, while costly, increases productivity, thus higher prices induce more integration (the idea is that at low prices, increases in revenues coming from enhaunced productivity are too small to justify the cost; whereas at high prices the revenue benefit exceeds the integration cost). Trade policy provides a source of exogenous price variation to asses the validity of this theoretical prediction. They construct firm level indices of vertical integration for a large set of countries and industries and exploit cross-section and time-series variation in import tariffs to examine their impact on firm boundaries. They focus on competitive sectors in order to rule out alternative mechanism that could generate a positive relation between tariffs and vertical integration. They conclude that output prices are a key determinant of vertical integration.
} 
a negative relationship between international openness and a motive for vertical integration thus supporting the theoretical statement by McLaren (2000). ${ }^{12}$

On top of the effects of international trade, some empirical contributions analyse the role of contract enforcement on firms' vertical structure. Pascali (2013) develops a model with incomplete contracts studying the interactions among trade barriers, contracting costs, technology intensity, and the extent of vertical integration. He also investigates these predictions through a cross-country analysis at firm level. The main empirical findings, consistent with theory, are that the likelihood to integrate vertically is decreasing in the quality of domestic contracting institutions and in international openness. The emerging policy advice in order to reduce the welfare costs associated with vertical integration is that "if improving home institutions is not feasible, then an equivalent solution is to reduce the trade barriers to the import of intermediates." Somewhat similarly, we find some substitutability between glocal policies and international openness in affecting the incentives to vertically integrate. Other cross-country empirical contributions on the effects of the institutional environment on the vertical boundaries of firms are Macchiavello (2012) and Acemoglu et al. (2009). These studies are at industry-level and analyse the role of financial development. ${ }^{13}$

The rest of the paper is organized as follows. We present the model in Section 2. We proceed with the equilibrium analysis in the closed and in the open economy in Sections (3) and (4) respectively. We discuss our results in terms of effective policies in Section (5). Formal details, definitions, proofs and figures are relegated in the Appendix.

\footnotetext{
${ }^{12}$ Recently, Atalay et al. (2014) study the relationship between vertical integration and input flows using microdata from two sources, the US Economic Census and the Commodity Flow Survey, and aggregate data from the Annual Wholesale Trade Survey and the Annual Retail Trade Survey. Departing from previous literature, they find that "most vertical ownership does not appear to be primarily concerned with facilitating physical goods movements along a production chain within the firm, as is commonly presumed. Upstream units ship surprisingly small shares of their output to their firms' downstream establishments." Rather, their results suggest that "a primary purpose of ownership may be to mediate efficient transfers of intangible inputs within firms".

${ }^{13}$ Other contributions focus on institutions quality and trade flows. In particular, Nunn (2007), using a multi-country dataset at industry level, tests whether the intensity of contract enforcement is a source of comparative advantage. Another important contribution is Levchenko (2007) showing that countries with better institutions specialize in goods that are institutionally dependent.
} 


\section{The model}

We consider a two-country model. In each country there is an industry with $N$ upstream $(U)$ firms and $N+H$ downstream $(D)$ firms. Each $D(U)$ can use (produce) only one unit of input. They can decide to vertically integrate. The $D$ firms produce differentiated final goods. Each final output needs an essential input produced by an $U$ firm. An input can be either specialized $(S)$ or flexible $(F)$. To produce (one unit of) input $S$, the $U$ firm incurs a sunk cost equal to $K_{S}$, whereas to produce (one unit of) input $F$, the $\mathrm{U}$ firm incurs a sunk cost $K_{F}=K_{S}(1-\alpha)<K_{S}$ with $\alpha \in(0,1)$ such that the cost gap is $\Delta K=K_{S}-K_{F}=\alpha K_{S} \cdot{ }^{14}$ Note that this gap depends on $\alpha$ which may capture a local/regional/national policy attempting to affect the cost of specialization. Think for example of investments in tertiary technological education, investments to stimulate IT start-up, and other input specific investments.

Firm $D_{j}$ (with $j=1, \ldots, N$ ) profit depends on the characteristics of the input received by firm $U$. If input $j$ is fully specialized for output $j$ it has a high value for $D_{j}$ (equal to $R_{j j}$ ) but it has no value for $D_{-j}$ (equal to $R_{j-j}=0$ ). Whereas if input $j$ is flexible it has value for both $D_{j}$ (equal to $e_{j j}$ ) and $D_{-j}$ (equal to $e_{j-j}$ ), however it is more valuable for output $j$ than for $-j\left(0<e_{j-j}<e_{j j}\right)$. Formally, we have the following ranking: ${ }^{15}$

$$
R_{j j}=1>e_{j j}>e_{j-j}>R_{j-j}=0
$$

As for firm $D_{N+h}$ (with $h=1, \ldots, H$ ), we assume that with some probability $\pi \in[0,1]$ there exists a specialized input for firm $D_{N+h}$, in other words, firm, say, $U_{k}$ (with $k=N-H+1, \ldots, N$ ) can produce a specialized input for both $D_{k}$ and $D_{N+h}$ with $k \neq N+h$. We thus consider $N$ upstream firms among which $H$ firms are defined as "special" because with probability $\pi$ they have an extra counterpart. ${ }^{16}$ This assumption reflects the idea that there exist different degrees of specialization. Namely, $\pi=0$ represents the full specialization case that is the input produced by firm $U_{k}$ is perfectly suitable for only the final good produced by $D_{k}$, so that firm $D_{N+h}$ has not a corresponding potentially specialized input and then it can only buy from $U_{j}$ and get value at most equal to $e_{j N+h} \cdot{ }^{17}$ As $\pi$ increases, the input becomes less specialized. When we arrive at $\pi=1$, it means that the features of the input are such that it can be adapted to at least two final goods, i.e. $U_{k}$ has an extra counterpart with certainty. In the latter case, even though our less specialized input could somewhat resemble a flexible input, this is not the case: this input is always specialized given that it could be adapted only to a subset of firms. ${ }^{18}$ Intuitively, given the dynamic path of the technologies, it may well happen that, in a certain point of this path, two firms (say $D_{k}$ and $D_{N+h}$ ) use the same specialized input

\footnotetext{
${ }^{14}$ More precisely, we denote this cost gap as specialization upgrade cost, see the Glossary in Appendix.

${ }^{15}$ We can think of producing a software specialized for a Nokia mobile phone, that has no value for a Samsung versus a flexible software thought for a Nokia but adaptable for a Samsung or other mobile phones.

${ }^{16}$ We can think of the "special" firms as firms that are abler than the others to capture the potential externalities (spillovers) of their investments in specialized inputs.

${ }^{17}$ Note that the first $N-H$ upstream firms may either produce a flexible or a fully specialized input $(\pi=0)$.

${ }^{18}$ We maintain the term "specialized" because differently from a flexible input that has a positive value for all $D$ firms, this specialized input is valuable only for $D_{k}$ and $D_{N+h}$.
} 
(for instance they could have invested in the same basic research, as a joint venture or as sponsors and beneficiaries of the same public research institute). The more we are far from this common point the lower is $\pi .^{19}$

Summarizing, $\frac{H}{N}$ is the share of $U$ firms that has a potential extra counterpart. Among this share, $\pi \frac{H}{N}$ effectively behaves as special and $(1-\pi) \frac{H}{N}$ effectively behaves as the remaining share of upstream firms in the market that is $\frac{N-H}{N} .{ }^{20}$ For the sake of description we label $k$ the representative firm belonging to the subset $H$ of special firms and $i$ the representative firm belonging to the complementary subset $N-H$.

Note that the asymmetric number of $U$ and $D$ firms implies that there are $H$ downstream firms that remain without a $U$ partner and so they do not produce at equilibrium. Consequently, there are $N$ couples that can match perfectly. While most of the theoretical contributions consider symmetric frameworks, we assume this asymmetry that we find more consistent with the real world. We can think of the non-matching firms as potential entrants that are not active ex post.

Consider the input production decision of $U_{j}$ (with $j=1, \ldots, N$ ). Under vertical separation (VS), the payoff of producing a specialized input is $-K_{S}+P_{j S}$, where $P_{j S}$ is the price of the specialized input; the payoff of producing a flexible input is $-K_{F}+P_{j F}$, where $P_{j F}$ is the price of the flexible input. Under vertical integration (VI) there are further internal "governance" costs equal to $L$ and the merger payoff of producing a specialized input is $-L-K_{S}+R_{j j}>0$ whereas the merger payoff of producing a flexible input is $-L-K_{F}+0<0 .^{21}$

The sequence of events is as follows (Figure 1):

i $\alpha$ is generated by the local/regional/national/international policies (policies).

ii Each couple of firms $U_{j}$ and $D_{j}$ jointly decide whether to vertically integrate (merger stage).

iii The sunk input production cost is incurred and so the value of each input $j$ produced by $U_{j}$ is revealed (production stage).

iv Bids are placed for inputs and exchange occurs (market stage).

We solve the model by backward induction, considering in turn the closed and the open economy. In particular we solve backwards the market stage, the production stage and the merger stage and as a result we find the equilibrium vertical structures and specialization decisions as a function of $\alpha$. As for the policies, note that this is not a proper stage of the game. Namely, according to the

\footnotetext{
${ }^{19}$ Different countries may clearly have different values of $\pi$ according to different institutional and private investments in basic versus specilized research, different protection of intellectual property private policies (patent versus secret), different matching opportunities.

${ }^{20}$ Formally, the number of special firms is a random variable described by a binomial distribution $B(H, \pi)$. Thus, the expected number of special firms is $H \pi$.

${ }^{21}$ Note that we do not consider any marginal cost of production. This allows us to neglect any vertical foreclosure motive linked to the vertical integration decisions. This is in line with Legros and Newman (2014) that point out how organizational features of the firms (e.g., vertical integration, delegation) are becoming more and more important factors in empirical and theoretical IO, in many cases more important than competitive pressure.
} 
different scenarios identified in the equilibrium analysis, we investigate the circumstances in which the policy maker can reach a specific objective in terms of firms' vertical structure and/or specialization decision. $^{22}$

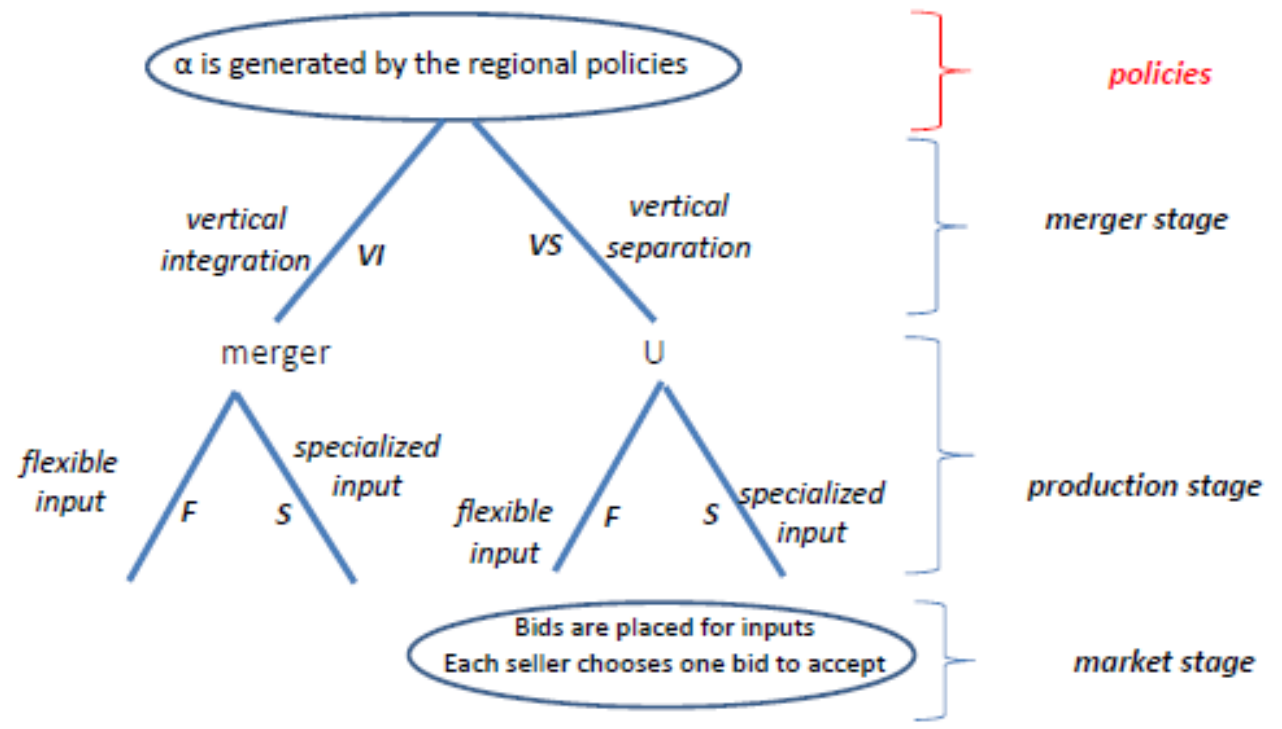

Figure 1: The sequence of events.

\footnotetext{
${ }^{22}$ We postpone to Section 5 a detailed discussion about the policy objective.
} 


\section{Equilibrium analysis in the closed economy}

We first focus on the closed economy version of the model. For each stage of the game, we analyse the choice of each special firm $k$ and the choice of each firm $i$ in turn.

\subsection{The market stage}

Consider the market stage. In the Appendix (7.2) we provide a detailed explanation for the price setting. In the following, we present the subgames and the corresponding equilibrium prices.

1 Vertical separation, flexible input: VS (F). The equilibrium bid by $D_{i}$ to firm $U_{i}$ is $P_{i F}=e_{i j}>0$. The equilibrium bid by $D_{k}$ to firm $U_{k}$ is $P_{k F}=\pi e_{k k}+(1-\pi) e_{k j}$.

2 Vertical separation, specialized input: VS (S). The equilibrium bid by $D_{i}$ to $U_{i}$ is $P_{i S}=0$. The equilibrium bid by $D_{k}$ to $U_{k}$ is $P_{k S}=\pi R_{k k}$.

Clearly, whenever firms decide to merge (subgame 3, VI (F) and subgame 4, VI (S)), there is no market price setting because the input is tranferred at its marginal cost.

Typically, the risk of hold up leads the firm to produce a flexible input rather than a specialized input under vertical separation. Indeed for firm $i$, under vertical separation the equilibrium price of a specialized input is zero. Note however that the asymmetric structure of the industry (in particular the presence of $N+H$ downstream firms and $\pi \geq 0$ ) implies that the hold up problem is not necessarily complete for the special firms as $P_{k S} \geq 0$. More precisely, in our model the hold-up problem is mitigated with respect to McLaren (2000) as while in McLaren the hold up could be complete also for flexible inputs, that is $P_{i F}=0,{ }^{23}$ here the equilibrium input price $P_{i F}$ is strictly positive.

\subsection{Production stage}

In the production stage the $U$ firms take the flexible/specialized decisions.

Define

$$
\pi^{F} \equiv \frac{\alpha K_{S}+e_{k j}}{R_{k k}-e_{k k}+e_{k j}}
$$

and

$$
\Delta \equiv R_{j j}-e_{j j}
$$

$\Delta$ represents the gross specialization upgrade gain: throughout the paper we will focus on the nontrivial case $\Delta>L$, that is the gain of specialization covers at least the cost of integration. Comparing subgames 1 and 2, and subgames 3 and 4, we obtain the following Lemma.

\footnotetext{
${ }^{23}$ More precisely, McLaren obtains incomplete hold-up by assuming the presence of a dude $P_{j F}>0$ only if there is at least one effective input (Proposition 4).
} 
Lemma 1 (i) Under VS each $U_{i}$ chooses to produce a flexible input; whereas each $U_{k}$ chooses to produce a flexible input if $\pi<\pi^{F}$ and chooses to produce a specialized input if $\pi>\pi^{F}$.

(ii) Under VI, the optimal choice is to produce a specialized input if $\alpha K_{S}<\Delta$, whereas it is optimal to produce a flexible input if $\alpha K_{S}>\Delta$.

Proof. See Appendix (7.3).

\subsection{Merger stage}

Consider next the merger stage, that is when VI or VS occurs.

Definition 1 VI takes place if and only if the profit of the VI entity is higher than the sum of the profits of the two vertically separated firms.

According to this definition, we can now solve the merger stage.

Lemma 2 (i) Firms $U_{k}$ and $D_{k}$ choose VI with a specialized input if $\pi<\pi^{F} \cup \alpha K_{S}<\Delta-L$; in all other cases VS occurs. In case of VS, the production/use of a flexible input occurs if $\alpha K_{S}>\Delta$ and if $\alpha K_{S} \in(\Delta-L, \Delta) \cup \pi<\pi^{F}$, otherwise specialization occurs.

(ii) Firms $U_{i}$ and $D_{i}$ choose VI with a specialized input if $\alpha K_{S}<\Delta-L$ and VS with a flexible input if $\alpha K_{S}>\Delta-L$.

Proof. See Appendix (7.4).

These conditions emphasize the potential role of institutions $(\alpha)$ in driving the integration and in turn the specialization decisions. ${ }^{24}$

\subsection{Equilibrium}

Solving for the VI and VS decisions of firms we obtain the following equilibria according to the specialization upgrade cost $\alpha K_{S}$.

Proposition 1 (i) Consider the case $\alpha K_{S}<\Delta-L$. At equilibrium, VI with a specialized input occurs for all firms if $\pi<\pi^{F}$. If instead $\pi>\pi^{F}$, we observe different behaviors: VS with specialized input for each firm $k$ and VI with a specialized input for each firm $i$.

(ii) Consider the case $\alpha K_{S} \in(\Delta-L, \Delta)$. At equilibrium, VS with a flexible input occurs for all firms if $\pi<\pi^{F}$. If instead $\pi>\pi^{F}$, we observe different behaviors: VS with a specialized input for each firm $k$ and VS with a flexible input for each firm $i$.

(iii) Consider finally the case $\alpha K_{S}>\Delta$. At equilibrium, VS with a flexible input occurs for all firms.

Proof. See Appendix (7.5). 

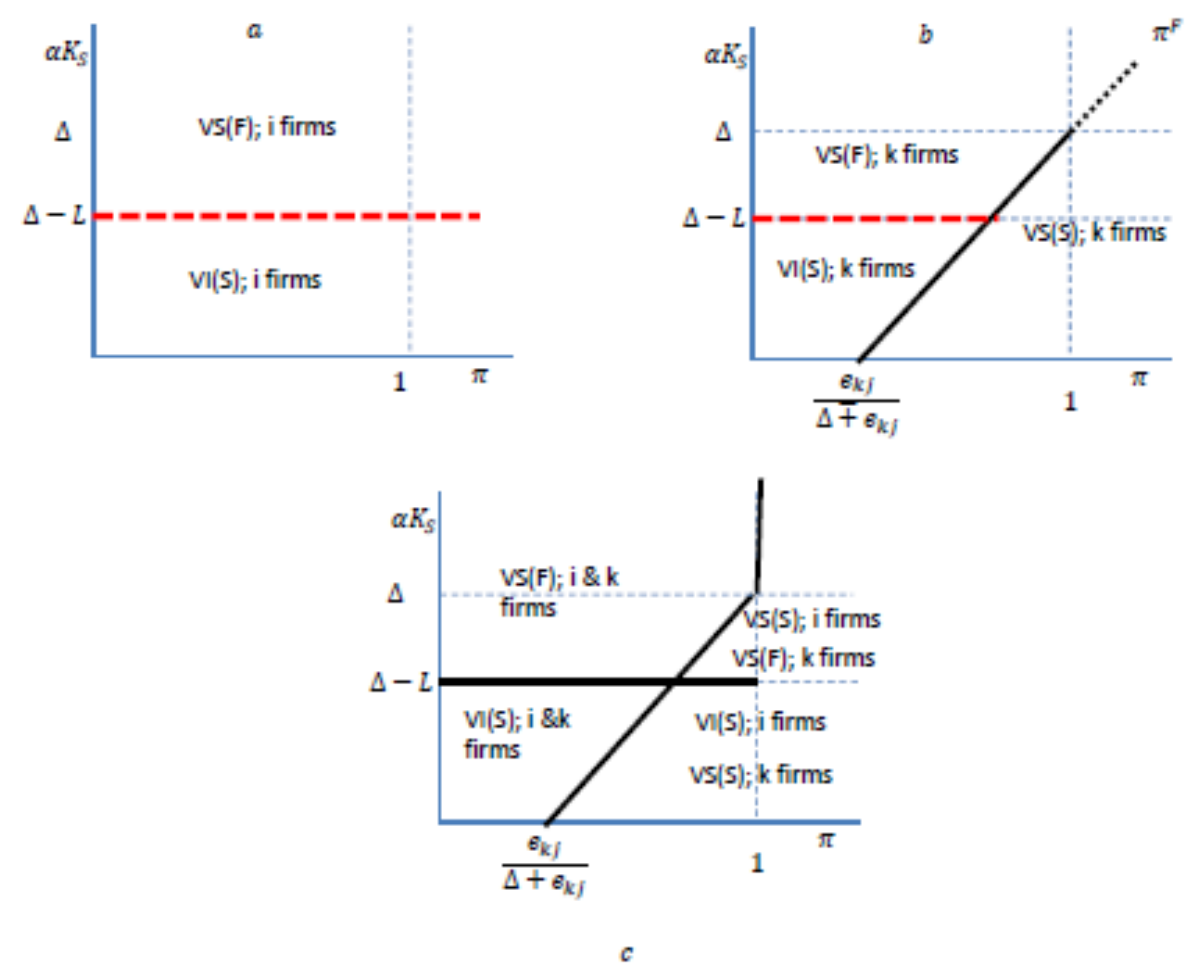

Figure 2: Closed Economy Equilibrium

Figure 2 displays firms' equilibrium behaviors in the closed economy. As far as the equilibrium behaviors of the firms $i$ are concerned (Figure 2a), the relevant threshold is $\alpha K_{S}=\Delta-L=$ $R_{i i}-e_{i i}-L$. Starting from the idea that going from a flexible to a specialized input implies an upgrade, an improvement of the quality of the input, we define $\alpha K_{S}$ the specialization upgrade cost. Similarly, we define $\Delta-L$ the net specialization upgrade gain, that is the hold-up free gain (given that integration guarantees full insurance against the risk of hold-up). It is then intuitive that as long as $\alpha K_{S}>\Delta-L$, that is the upgrade cost is not covered by the net upgrade gain, integration is not profitable.

As for the special firms, looking at Figure $2 b$, the most important difference with respect to the other firms is that for some values of the parameters, vertical integration is not necessary anymore in order to have specialization; in other words, at equilibrium the special firms can choose VS (S). This is due to the attenuated hold-up. More precisely, we get a further relevant threshold, $\pi^{F}\left(\alpha K_{S}\right)$, increasing with $\alpha K_{S}{ }^{25}$

Rephrasing our equilibrium results according to the probability of being special $\pi$, we conclude the following.

\footnotetext{
${ }^{24}$ For example, several studies analyse the role of Key Enabling Technologies (KETs) as an important component of a smart specialization strategy implemented by regions. In particular, OECD (2011) and COM (2011) argue that many future goods and services will be driven by KETs such as semiconductors, advanced materials, photonics and nanotechnology.

${ }^{25}$ In Appendix, we provide a more detailed description of Figure $2 \mathrm{~b}$.
} 
Corollary 2 In the closed economy, (i) if $\pi \in\left[0, \pi^{F}\right]$, there is perfect correspondence between the firm vertical structure and the input specialization decision: at equilibrium all firms behave in the same way.

(ii) If $\pi \in\left[\pi^{F}, 1\right]$, there is not anymore a perfect correspondence between the firm vertical structure and the input specialization decision: at equilibrium, firms behave in different ways.

For low values of $\pi\left(\pi \in\left[0, \pi^{F}\right]\right)$ at equilibrium all firms behave in the same way, they either stay VS with F or VI with S. This result is in line with McLaren (p. 1246): "there is an exact correspondence between ownership structure and technology choice". Note that when $\pi$ is low $(\pi<$ $\left.\pi^{F}\right)$, it is as if any $U_{k}$ were identical to any firm $U_{i}$. Given $\pi^{F}=\frac{\alpha K_{S}+e_{k j}}{\Delta-e_{k j}}$, this is more likely, the lower is $\Delta$ and the higher is $\alpha K_{S}$. For high values of $\pi\left(\pi \in\left[\pi^{F}, 1\right]\right)$ at equilibrium, firms behave in different ways. If VI occurs, independently of $\pi$, the VI firms choose to produce a specialized input; if VS occurs, firm $U_{i}$ always chooses a flexible input, whereas $U_{k}$ chooses either a specialized or a flexible input depending on the parameters. 


\section{Equilibrium analysis in the open economy}

The open economy is described as follows. There are two countries: 1 and 2. In order to focus on the vertical structure / input specialization decision, we assume that only inputs can be traded, that is the final goods are nontraded (for instance because final goods of country 2 are unattractive to consumers of country 1 or because of too high trade costs related (only) to final goods). ${ }^{26} \mathrm{We}$ assume that countries are perfectly symmetric. Consequently, when we open the economy each $U_{j}^{1}$ can sell her input to $D_{j}^{1}, D_{-j}^{1}$ and incurring a trade cost $t$ to $D_{j}^{2}$ and $D_{-j}^{2}$. The superscript refers to the country $\{1,2\}$ and the lowerscript refers to the firm $\{j,-j\}$. Formally, each $U$ firm becomes "special" in the sense that it can produce an input that is specialized for at least two $D$ firms (one per country). The immediate consequence of opening the (input) market is thus a change in the bargaining power between the firms. The bargaining power of the $\mathrm{U}$ producers increases and that of the D firms decreases. Each $U_{j}^{1}$ can vertically integrate with $D_{j}^{1}\left(D_{j}^{2}\right)$ incurring fixed cost $L^{1}\left(L^{2}\right) .{ }^{27}$ It is worth emphasizing that opening the market implies a rise in market thickness that however is distinct from an increase in competition. In our paper, in line with McLaren (2000) as well as with many of the contributions on this area, competition effects are absent (see McLaren 2003). ${ }^{28}$

\subsection{The market stage}

Consider the market stage. Defining

$$
\varepsilon \equiv e_{i i}-e_{i j}
$$

as the fitting gain for a flexible input, we can write $R_{i i}-e_{i j}=\Delta+\varepsilon$. In the Appendix (7.2) we provide a detailed explanation for the price setting. In the following, we present the subgames and the corresponding equilibrium prices.

1 Vertical separation, flexible input: VS (F). The equilibrium price received by firm $U_{i}$ depends on the level of trade cost $t$ :

$$
P_{i F}^{*}=\left\{\begin{array}{l}
e_{i j} \text { if } t>\varepsilon \\
e_{i i}-t \text { else }
\end{array} .\right.
$$

The equilibrium price for a special firm $U_{k}$ is:

$$
P_{k F}^{*}=\left\{\begin{array}{c}
\pi e_{k k}+(1-\pi) e_{k j} \text { if } t>\varepsilon(1-\pi) \\
e_{k k}-t \text { else }
\end{array} .\right.
$$

2 Vertical separation, specialized input: VS (S). The equilibrium price for a firm $i$ is $P_{i S}^{*}=R_{i i}-t$. Whereas the equilibrium price for a special firm $U_{k}$ is:

$$
P_{k S}^{*}=\left\{\begin{array}{cl}
\pi R_{k k} & \text { if } t>R_{k k}(1-\pi) \\
R_{k k}-t \text { else }
\end{array} .\right.
$$

\footnotetext{
${ }^{26}$ We acknowledge that this is a simplifying assumption. However it is line with previous contributions, like McLaren (2000) whose theoretical model have been empirically substantiated, see for instance Chongvilaivan and Hur (2012).

${ }^{27}$ Note that the ranking between $L^{1}$ and $L^{2}$ can be either $L^{1}>L^{2}$ or $L^{1} \leq L^{2}$ because of country-specific cost to create a firm.

${ }^{28}$ For a focus on the pro-competitive effects of international trade in the presence of the hold-up problem see, among others, Wes (2000) that focuses on the free trade of the downstream good.
} 
In subgames 3, VI (F) and 4, VI (S), there is no market price setting because the input is tranferred at its marginal cost.
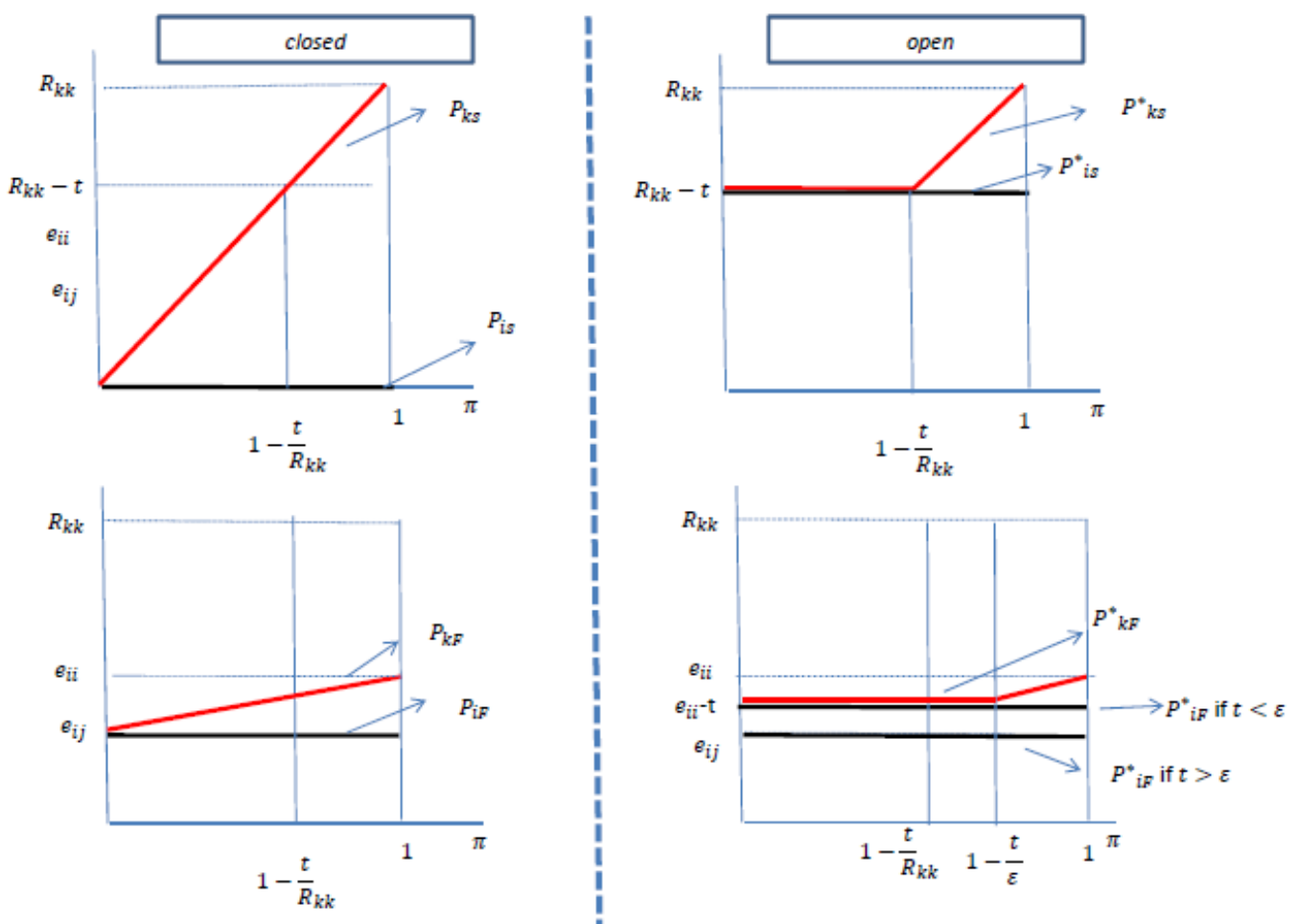

Figure 3: Market Stage

Figure 3 displays the market stage equilibrium prices as a function of $\pi$ : the left panel shows the closed economy case and the right panel shows the open economy case. Looking at this figure, we can compare the hold-up problem (reflected in the prices) faced by firms when dealing with a specialized input versus a flexible input.

Consider first the decision of producing a specialized input (top of Figure 3). All firms gain from opening the market in terms of hold-up: namely, for any value of $\pi$, the hold up for the $i$ firms, that is maximal in the closed economy, decreases $\left(P_{i S}=0<P_{i S}^{*}\right)$, and the hold-up for the special firms is at most equal $\left(P_{k S}<P_{k S}^{*}\right.$ for $\pi<1-\frac{t}{R_{k k}}$ and $P_{k S}=P_{k S}^{*}$ for $\left.\pi>1-\frac{t}{R_{k k}}\right)$. More precisely, the special firm strictly prefers the open economy with respect to the closed economy as long as $\pi$ is low, and it is indifferent when $\pi$ is high. The intuition is that for low values of $\pi$, the $k$ firms are "not very special", that is they are very similar to the $i$ firms. In particular, in the closed economy the special firms are subject to a lower hold-up than the other firms, for any $\pi>0$; whereas, in the open economy, for $\pi$ low enough, the market stage equilibrium prices are equal for all firms, and for $\pi$ high enough the $k$ firms get a higher price than the $i$ ones. Note however that this price difference is lower than in the closed economy. 
Consider next the decision of producing a flexible input (bottom of Figure 3). Firms' preferences depend on the trade costs, $t$. First, as long as $t>\varepsilon$, nothing changes when moving from the closed to the open economy (the threshold $\pi=1-\frac{t}{\varepsilon}<0$ ). If instead $t<\varepsilon$, all firms gain from opening the market: namely, for any value of $\pi$, the hold up for the $i$ firms decreases $\left(P_{i F}<P_{i F}^{*}\right)$, and the hold-up for the $k$ firms is at most equal $\left(P_{k F}<P_{k F}^{*}\right.$ for $\pi<1-\frac{t}{\varepsilon}$ and $P_{k F}=P_{k F}^{*}$ for $\left.\pi>1-\frac{t}{\varepsilon}\right)$. Again, the $i$ firms strictly prefer to open the market, whereas the $k$ firms have a strict preference for $\pi$ low and they are indifferent between the closed and the open economy for $\pi$ high. ${ }^{29}$

In sum we can say that in the closed economy the $k$ firms are always better off than the $i$ firms, whereas this relative advantage becomes nil in the open economy, i.e., for low values of $t$.

\subsection{Production stage}

In the production stage the $U$ firms take the flexible/specialized decisions.

Comparing subgames 1 and 2, and subgames 3 and 4, we obtain the following Lemma.

Define

$$
\tilde{\Delta}=\text { intermediate value }\left\{\Delta, \Delta+(1-\pi) \varepsilon-t, \Delta+(1-\pi)\left(\varepsilon-R_{k k}\right)\right\} \text {. }
$$

Lemma 3 (i) Under $V S$, each $U_{i}$ chooses to produce a flexible input if $\alpha K_{S}>\min \{\Delta, \Delta+\varepsilon-t\}$ and chooses to produce a specialized input if $\alpha K_{S}<\min \{\Delta, \Delta+\varepsilon-t\}$; each $U_{k}$ instead chooses to produce a flexible input if $\alpha K_{S}>\widetilde{\Delta}$ and chooses to produce a specialized input if $\alpha K_{S}<\widetilde{\Delta}$.

(ii) Under VI, the optimal choice is to produce a specialized input if $\alpha K_{S}<\Delta$, whereas it is optimal to produce a flexible input if $\alpha K_{S}>\Delta$.

Proof. See Appendix (7.3).

\subsection{Merger stage}

Consider next the merger stage, that is when VI or VS occurs. Given definition (1), we find the following result.

Define

$$
\begin{aligned}
& \hat{\Delta}=\text { intermediate value }\left\{\Delta, \Delta+(1-\pi) \varepsilon-t, \Delta-\min \left\{L^{1}, L^{2}\right\}\right\}, \\
& \breve{\Delta}=\text { intermediate value }\left\{\Delta, \Delta+\varepsilon-t, \Delta-\min \left\{L^{1}, L^{2}\right\}\right\} .
\end{aligned}
$$

Lemma 4 (i) Firms $U_{k}$ and $D_{k}$ choose VI with a specialized input if $\alpha K_{S} \in[\Delta+\max \{(1-\pi) \varepsilon-$ $\left.\left.t,(1-\pi)\left(\varepsilon-R_{k k}\right)\right\}, \Delta-\min \left\{L^{1}, L^{2}\right\}\right] ;$ in all other cases VS occurs. In case of VS, the production/use of a flexible input occurs if $\alpha K_{S}>\hat{\Delta}$ and specialization occurs if $\alpha K_{S}<\tilde{\Delta}$.

(ii) Firms $U_{i}$ and $D_{i}$ choose VI with a specialized input if $\alpha K_{S} \in\left[\Delta+\varepsilon-t, \Delta-\min \left\{L^{1}, L^{2}\right\}\right]$; in all other cases VS occurs. In case of VS, the production/use of a flexible input occurs if $\alpha K_{S}>\breve{\Delta}$ and specialization occurs if $\alpha K_{S}<\min \{\Delta, \Delta+\varepsilon-t\}$.

\footnotetext{
${ }^{29}$ Note that the relevant threshold of $\pi$ for the flexible input production is lower than the threshold identified for the specialized input production, i.e. $1-\frac{t}{\varepsilon}>1-\frac{t}{R_{k k}}$.
} 
Proof. See Appendix (7.4)

Open economy - $i$ firms

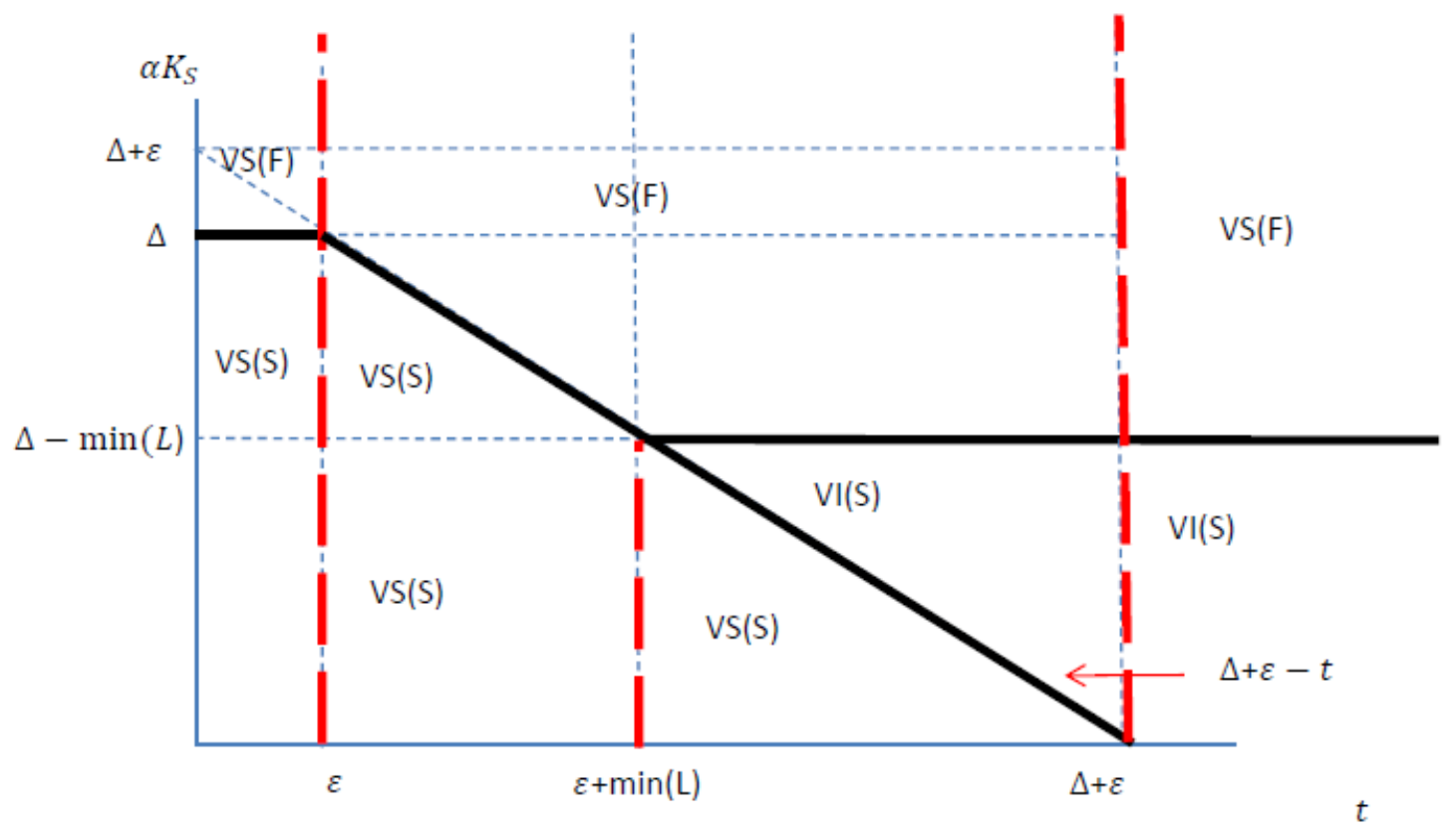

Figure 4: Merger Stage ( $i$ firms)

Figure 4 displays the merger stage equilibrium for the $i$ firms as a function of $t$. The comparison with the closed economy (Figure 2a) depends on the value of the trade costs. Namely, we identify the following three ranges of $t$ : low values of $t$, that is $t<\varepsilon+\min L,{ }^{30}$ intermediate values of $t$, that is $t \in[\varepsilon+\min L, \Delta+\varepsilon]$ and high values of $t$, that is $t>\Delta+\varepsilon$.

When $t$ is low, VI is not anymore an equilibrium, in particular the area where in the closed economy we had VI is completely replaced by VS (S). The equilibrium VS (S) takes also part of the area where in the closed economy we had VS $(\mathrm{F})$. When $t$ is intermediate, the equilibrium VS $(\mathrm{F})$ takes place for the same parameters ranges as in the closed economy, whereas the equilibrium VI (S) is in part replaced by VS $(\mathrm{S})$. Finally, when $t$ is high, we get the same equilibria as in the closed economy. In particular, $t>\Delta+\varepsilon$ is so high to cancel out any gain from opening the market. ${ }^{31}$

\footnotetext{
${ }^{30}$ In the figures, the term $\min L$ corresponds to $\min \left\{L^{1}, L^{2}\right\}$.

${ }^{31}$ Note that in the open economy, as long as $t$ is low enough, i.e., $t<\varepsilon+\min L$, the specialization area increases. This threshold can be seen as the opportunity cost of being flexible given by the sum of the fitting gain for a flexible input $(\varepsilon)$ and the cost of vertical integration ( $\min L$ that represents a gain for not integrating).
} 


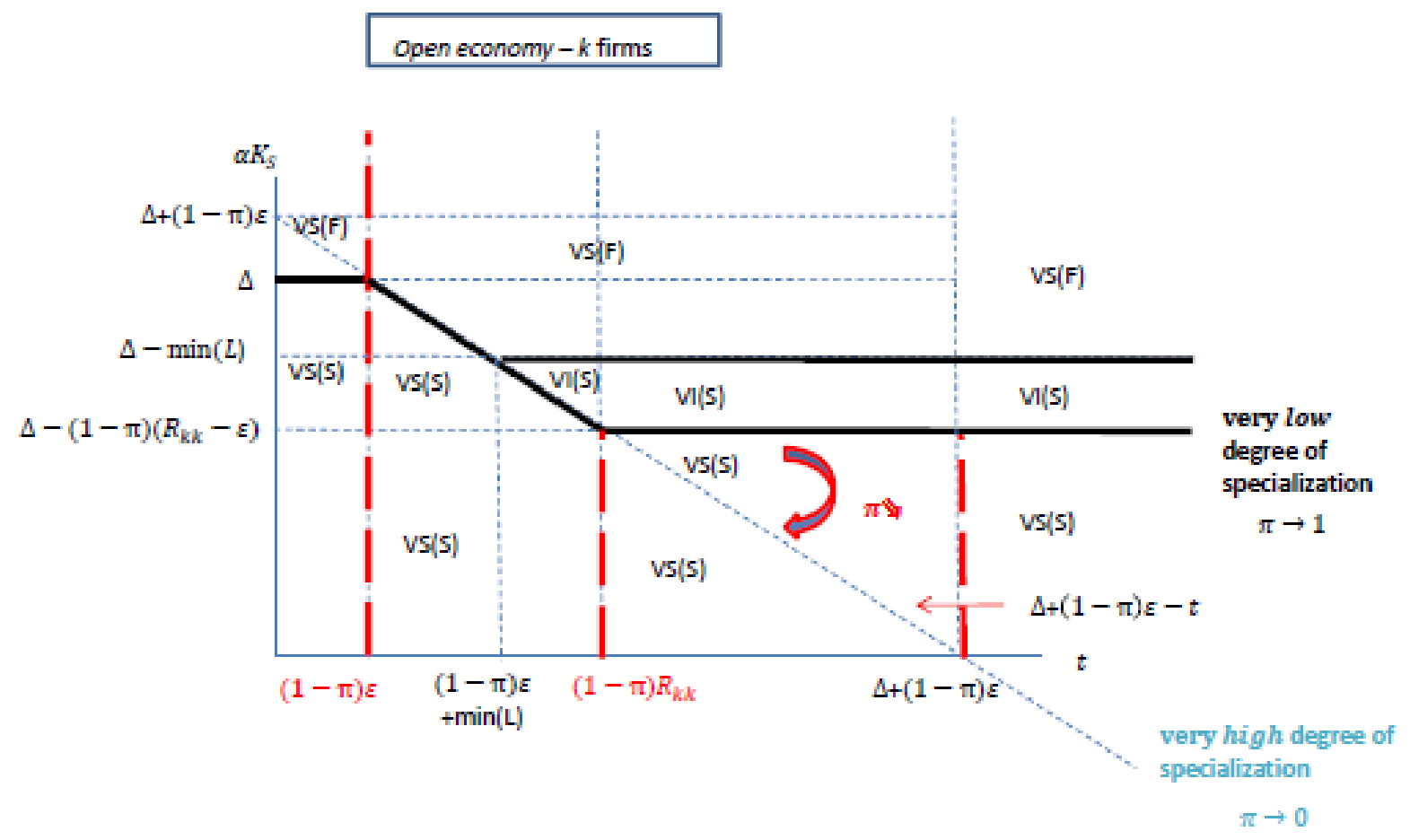

Figure 5: Merger Stage (special firms)

Figure 5 displays the merger stage equilibrium for the $k$ firms as a function of $t .^{32}$ In order to make a comparison between $i$ and $k$ firms in the open economy (Figure 5 versus Figure 4 ) consider the following three ranges of $t$ : low values of $t$, that is $t<(1-\pi) \varepsilon+\min L$, intermediate values of $t$, that is $t \in[(1-\pi) \varepsilon+\min L, \Delta+(1-\pi) \varepsilon]$ and high values of $t$, that is $t>\Delta+\varepsilon(1-\pi)$. Firstly, note that these thresholds for the $k$ firms are less than or equal to the thresholds identified for the $i$ firms, depending on $\pi$ : as $\pi \rightarrow 0$, these thresholds equalize. When $t$ is low, we get a correspondence between the two types of firms in terms of equilibria: this area reduces as $\pi$ increases, also for any $\pi>0$, the area VS (S) shrinks. When $t$ is intermediate, for firms $k$ the area VI (S) is in part replaced by VS (S) with respect to the $i$ firms: as $\pi$ increases the area VI (S) shrinks and tends to zero for $\pi$ high enough. Note that this also happens in the closed economy for the special firms. Finally, when $t$ is high, the main difference with respect to the $i$ firms is that the area VS (S) does not disappear, and it increases with $\pi$. Note that for this area to shrink to zero also for the special firms we need either $\pi$ that goes to zero or very high values of $\left(R_{k k}-\varepsilon\right)$, so that $\Delta-(1-\pi)\left(R_{k k}-\varepsilon\right) \rightarrow 0$.

\footnotetext{
${ }^{32}$ Note that, in contrast with the case of the $i$ firms, we cannot compare this figure with Figure $2 \mathrm{~b}$ where the behaviors of the special firms depend on $\pi$. We postpone the comparison of the open versus the closed economy behaviors of the $k$ firms to the comments of Figure 6 .
} 


\subsection{Equilibrium}

Solving the VI and VS decisions of $k$ and $i$ firms we obtain the following results according to the specialization upgrade cost $\alpha K_{S}$.

Proposition 2 (i) Consider the case of (relatively) low values of $\alpha K_{S}$. At equilibrium, VS with a specialized input occurs for all firms when $t<(1-\pi) R_{k k}$ if $\alpha K_{S}<\min \{\Delta, \Delta+(1-\pi) \varepsilon-t\}$ and when $t>(1-\pi) R_{k k}$ if $\alpha K_{S}<\min \left\{\Delta+(1-\pi)\left(\varepsilon-R_{k k}\right), \Delta+\varepsilon-t\right\}$.

(ii) Consider the case of (relatively) intermediate values of $\alpha K_{S}$. At equilibrium, VI with a specialized input occurs for all firms if $\alpha K_{S} \in\left[\Delta+\max \left\{\varepsilon-t,(1-\pi)\left(\varepsilon-R_{k k}\right)\right\}, \Delta-\min \left\{L^{1}, L^{2}\right\}\right]$; we observe instead that if $\alpha K_{S} \in\left[\Delta+\max \left\{(1-\pi) \varepsilon-t,(1-\pi)\left(\varepsilon-R_{k k}\right)\right\}, \Delta+\min \left\{-\min \left\{L^{1}, L^{2}\right\}, \varepsilon-t\right\}\right]$, $V I$ with a specialized input occurs for the firms $k$ and VS with a specialized input occurs for the firms i; if $\alpha K_{S} \in\left[\Delta+\max \left\{(1-\pi) \varepsilon-t,-\min \left\{L^{1}, L^{2}\right\}\right\}, \min \{\Delta, \Delta+\varepsilon-t\}\right]$, VS with a flexible input occurs for the firms $k$ and VS with a specialized input occurs for the other firms i; finally, if $\alpha K_{S} \in\left[\Delta+\varepsilon-t, \Delta+(1-\pi)\left(\varepsilon-R_{k k}\right)\right], V S$ with a specialized input occurs for the firms $k$ and VI with a specialized input occurs for the firms $i$.

(iii) Consider finally the case of (relatively) high values of $\alpha K_{S}$. At equilibrium, VS with a flexible input occurs for all firms if $\alpha K_{S}>\left\{\Delta, \Delta-\min \left\{L^{1}, L^{2}\right\}, \Delta+\varepsilon-t\right\}$.

Proof. See Appendix (7.5).

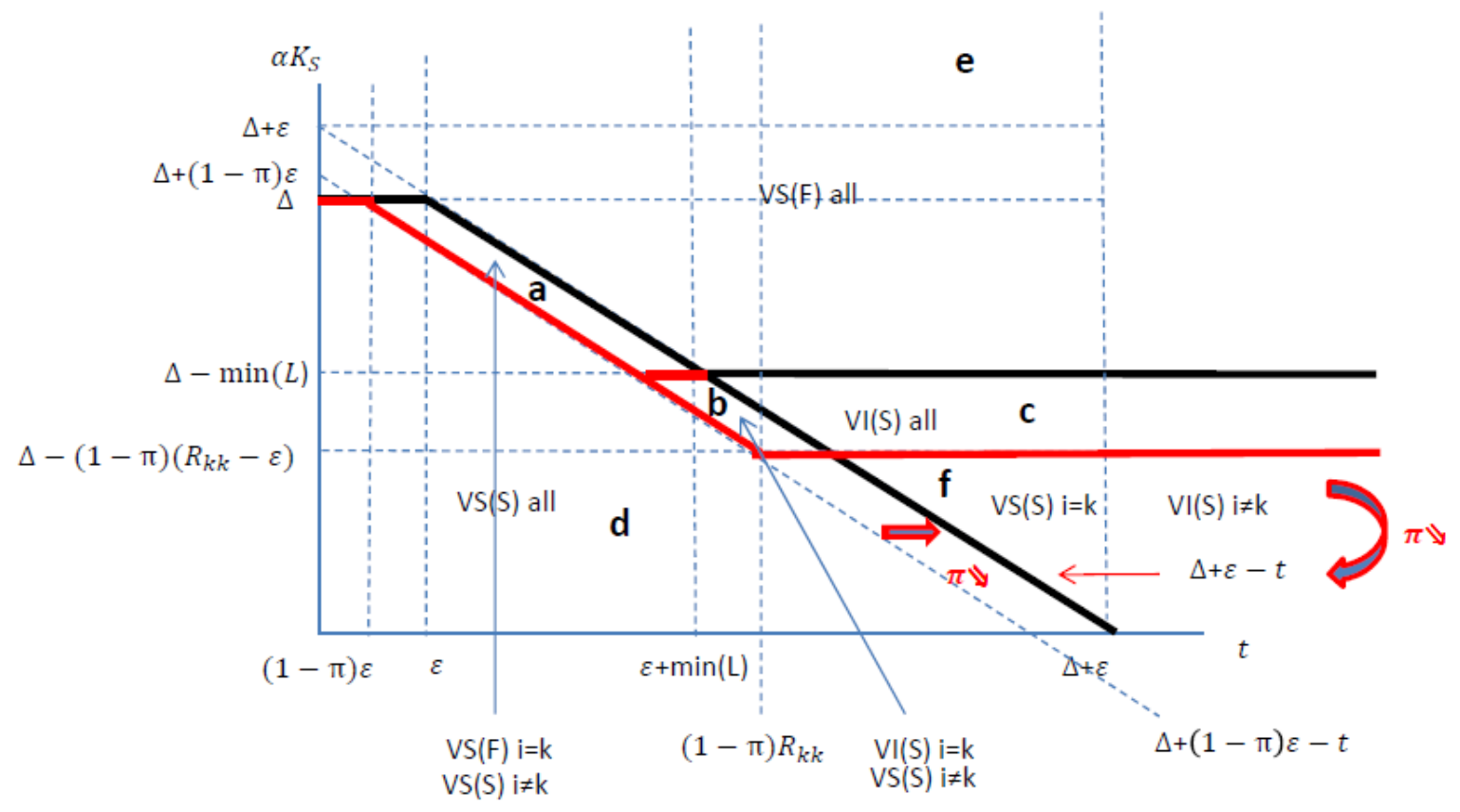

Figure 6: Open Economy Equilibrium 
The intuition behind these results is as follows. As long as the specialization upgrade cost is relatively low, as one could expect, specialization takes place for all firms, however, firms decide to stay vertically separated because the hold-up is very mitigated with respect to the closed economy (area d of Figure 6). This equilibrium is new with respect to the closed economy.

On the other extreme, whenever the specialization upgrade cost is relatively high, all firms opt for a flexible input and also their vertical structure remains separated. In sum, their production and merger decisions are not affected by opening the market (area e of Figure 6).

Things become more complex and differences arise among firms' behaviors for not extreme values of the specialization upgrade cost. In particular, the equilibrium behaviors depend on $t$ and on $\pi$. As far as $t$ is concerned, for relatively large values of $t$ (areas $\mathrm{c}$ and $\mathrm{f}$ ), firms' behaviors are intuitive: all firms behave as in the closed economy. In particular, in area $\mathrm{c}$ they still vertically integrate because of the hold-up problem; whereas in area $\mathrm{f}$, the $i$ firms vertically integrate and the $k$ firms remain vertically separated because the hold-up problem is milder for the $k$ than for the $i$ firms (given that $t$ is high enough for the relative advantage of the $k$ firms to be restored). In contrast, for relatively low values of $t$ (areas a and $\mathrm{b}$ ), the interaction between $t$ and $\pi$ determine the equilibrium behaviors. In area a, $t$ is not strong enough for the $i$ firms to imply the switch from specialized to flexible input ( $i$ firms behave as in area $\mathrm{d}$ ); as for the $k$ ones, the effect of $t$ is different because it is combined with $\pi$ and the result is that this effect is strong enough to imply the switch from specialized to flexible input (the $k$ firms behave as in area e). As for area $\mathrm{b}$, the combined effect of $t$ and $\pi$ is strong enough for the $k$ firms to imply the switch from vertical separation to vertical integration (the $k$ firms behave as in area $\mathrm{c}$ ); as for the $i$ firms, $t$ is not strong enough to imply the switch from vertical separation to vertical integration ( $i$ firms behave as in area $\mathrm{d}$ ). At first glance, the behaviors in areas a and $\mathrm{b}$ are counterintuitive, because, given the open economy, one could expect all firms to reach the best equilibrium (area d) simultaneously, whereas the $k$ firms need, ceteris paribus, lower levels of $t$ with respect to the $i$ ones. The intuition is that, given that the $k$ firms have a relative advantage with respect to the $i$ firms in the closed economy, they need a higher gain (lower $t$ ) to give up the closed economy equilibrium. Note that areas a and b increase with $\pi$ that is a measure of how much the $k$ firms are special in the closed economy.

Remark 1 In the open economy, as $t$ decreases the special firms become (relatively) less and less special.

It follows from Proposition 2 that:

Corollary 3 In the open economy, there is never a perfect correspondence between the firms'vertical structure and the specialization decision (for any value of $\pi \in[0,1]$ ), i.e., a specialized input can be produced by both a vertically integrated entity or a vertically separated producer.

If a policy maker can affect either the vertical structure (that is the cost $L$ ) or the specialization decision (that is the cost $\alpha$ ), when there is perfect correspondence, the policy maker can act on 
either instrument and be sure about the result. This is what happens in the closed economy. In the open economy, instead, this does not hold anymore: the policy maker, to reach a given equilibrium outcome need to act on both instruments.

Let us now analyse better the role of the special firms in our model. In the closed economy, as we see in Figure $2 \mathrm{~b}$, there exists a value of $\pi$ equal to $\pi^{F} \in(0,1]$ that defines a threshold below which the equilibrium behaviors of the $k$ firms is equal to the equilibrium behaviors of the $i$ firms. In the open economy, as stated by the following Corollary, this is not true anymore.

Corollary 4 In the open economy, in contrast with the closed economy, the only value of $\pi$ such that all firms behave in the same way for any value of the parameters is $\pi=0$.

Proof. It comes from the observation of Figure 6 . In areas a, $\mathrm{b}$ and $\mathrm{f}$ firms $k$ and firms $i$ behave in different ways. These areas disappear as soon as $\pi=0$ (and Figure 5 reduces to Figure 4 ).

Being special is closely related to the concept of open economy. In particular, in the closed economy the $k$ firms, for certain values of $\pi$, reach equilibrium behaviors (VS (S)) that the $i$ firms can reach only in the open economy. In other words, a special firm can be seen as a firm that manages to get the gain of the open economy in a closed world. In contrast, in an open world, being special becomes relatively less profitable for the presence of the trade cost. This implies that the equilibria for the $k$ firms are either different from the equilibria of the $i$ ones or they are the same but occur with a "delay" in the parameters. 


\section{Policies}

Once developed the equilibrium analysis, we here address the main question of the model: how can vertical integration decisions be influenced by policies at local/regional/national/international level?

So far, we have pointed out the role of the hold-up problem on firms' vertical organization decisions. We here focus on the main elements that in our model affect the degree of hold-up: degree of specialization, sunk cost (influenced mainly by the local/regional policy maker) and international openness (influenced mainly by the national/international policy maker). In the following we first describe the link between specialization and sunk cost, and then we analyse the role of the policy maker.

As far as the policy objective is concerned, we do not formalize a welfare function as in general the social ranking of the preferred vertical structure may be ambiguous. More precisely, it is plain that from a social point of view, the first best is an industry characterized by vertically separated firms that produce specialized inputs: this way the society saves the governance costs of vertical integration without trading off the value of the goods. On the other extreme, the worst outcome is vertical integration with flexible inputs. More generally, the social ranking of the preferred vertical structure is clear for a given specialization decision, i.e., $V S(S) \succ V I(S)$ and $V S(F) \succ V I(F)$. Nevertheless, it is ambiguous whether vertical separation and flexible input should be preferred to vertical integration and specialization.

Specialization and sunk cost In the model we have shown that the higher is the probability that the holdup arises, the higher is the probability that there is a perfect correspondence between the firm vertical structure and the input specialization decision.

The hold-up problem can influence the vertical structure and the specialization decision through two main factors: the number of downstream firms that can use the input produced by an upstream firm and the sunk cost of this input. The number of these downstream firms is a function of the degree of specialization $(\pi)$ and the level of international openness $(t)$. Formally, we take the probability of being special, $\pi$, as an inverse measure of specialization. Namely, whenever $\pi$ is zero or close to zero the input is very specialized (in the closed economy the input is perfectly suitable for only one downstream firm); on the other extreme, whenever $\pi$ approaches one it means that the features of this input are such that it can be adapted to two downstream firms. The international openness implies an increase in the number of downstream firms that can use the input (and so a reduction of the hold-up problem) for any level of $\pi$. Namely, when we open the market, for the $i$ firms the number of downstream firms becomes two, for the $k$ firms this number becomes (potentially) four.

As for the cost, manufacturing a specialized input implies higher sunk costs than manufacturing a flexible input. As a consequence, the risk of hold-up in the first case is higher than in the second case (it is nil in case of flexible inputs by definition). These costs can be influenced by the policy makers' decision $(\alpha)$ through several channels: basic research, specific public IT investments, public research institutions and postgraduate courses that focuses on a specific specialized inputs, fiscal policies that 
reduce the costs of specialization, etc. All these policies can reduce the cost of specialization for a single firm or for a particular cluster and consequently influence the final equilibrium.

Summarizing, in our model, the hold-up problem is a decreasing function of $\pi$ and an increasing function of $\alpha$ and $t$.

Effective policies Our model shows that the equilibria, in terms of vertical structure and specialization decision, depend on the specialization costs $(\alpha)$, the integration costs $(L)$ and the trade costs $(t)$. Manipulating these parameters, it is thus possible, under some circumstances, to affect firms' equilibrium vertical organization. In the following, according to the different scenarios identified in the model, we analyse the circumstances in which the policy maker can reach a specific objective. We define effective policies all policies that influence the vertical structure of the firms/clusters by increasing or decreasing the specialization upgrade costs, the vertical organization costs and/or the trading cost.

For the sake of description, we here label the relevant parameters' thresholds that we have identified in the equilibrium analysis. We define and rank the following thresholds for the specialization upgrade costs according to different values of $\alpha: \alpha_{1}$ is such that $\alpha_{1} K_{S}=\Delta, \alpha_{2}$ is such that $\alpha_{2} K_{S}=\Delta-L$ and $\alpha_{3}$ is such that $\alpha_{3} K_{S}=\Delta-(1-\pi)\left(R_{k k}-\varepsilon\right)$. As for $t$, we have: $t_{1}=\Delta+(1-\pi) \varepsilon$, $t_{2}=(1-\pi) R_{k k}$ and $t_{3}=(1-\pi) \varepsilon$. Finally we define $\pi_{1}=\pi^{F}$ and $\pi_{2}=1-\frac{L}{\Delta+e_{k j}}$.

The policy maker by influencing the specialization upgrade cost and the trading costs can move firms/clusters from one equilibrium to another. The realization of these policies is influenced by the degree of specialization $(\pi)$. In particular, in the closed economy (very high level of $t$ ), the main policy instrument is represented by $\alpha$. Namely, looking at Figure 7:

i) whenever the inputs are very specialized, i.e. $\pi<\pi_{1}$, the policy maker can achieve a VS equilibrium (with flexible input) by implementing policies that imply a high specialization upgrade cost i.e., $\alpha>\alpha_{2}$ or can achieve a VI equilibrium (with specialized input) by implementing policies that imply $\alpha<\alpha_{2}$.

ii) whenever the inputs are not very specialized, i.e. $\pi>\pi_{1}$, the policy maker cannot influence the special firms/clusters' vertical structure (VS is the unique equilibrium) but can influence their specialization decision affecting the level of $\alpha$.

Note that these policies are always effective when the hold-up problem is maximal (as for the $i$ firms, characterized by $\pi=0)$ or it is sufficiently important $\left(\pi<\pi_{1}\right)$.

As for the open economy, the main policy instruments are represented by $\alpha$ and $t$. Namely looking at Figure 8:

iii) in the presence of low trading cost, i.e. $t<t_{2}$, the policy maker cannot influence the firms/clusters' vertical structure (VS is the unique equilibrium) but can influence their input production decision (specialized or flexible input). This is true for any level of specialization $\pi$ and any specialization upgrade $\operatorname{cost} \alpha$. 
iv) in the presence of high trading cost, i.e., $t>t_{2}$ the policy maker can achieve a VS equilibrium (with flexible input) by implementing policies that imply a $\alpha>\alpha_{2}$; furthermore the policy maker can achieve a VI equilibrium (with specialized input) by implementing policies that imply a $\alpha \in\left[\alpha_{3}, \alpha_{2}\right]$. This is true for any degree of specialization $\pi$. Finally, the policy maker can achieve a VS equilibrium (with specialized input) by implementing policies that imply a $\alpha<\alpha_{3}$ in case of high levels of $\pi$ and a VI equilibrium (with specialized input) in case of low levels of $\pi .^{33}$

The intuition behind these results is as follows. The effectiveness of the glocal policies $(\alpha)$ is higher the more is the importance of the hold-up problem. For the $k$ firms, that faces a low risk of hold-up compared with the $i$ firms, this policy is ineffective. The same reasoning holds when we move from the closed to the open economy.

Since the effects on the $k$ firms versus the $i$ ones are different, we could think of a measure of the policy effectiveness looking at the share of firms affected in terms of vertical organization $\left(\frac{N}{N}+\frac{(1-\pi) H}{N}=\frac{N-\pi H}{N}\right)$. Namely the lower are $\pi$ and $H$ the higher is the effectiveness of the policies.

Let us analyse the interaction between policies that affect the specialization upgrade cost $(\alpha)$ and the policies that affect the trading cost $(t)$. If the specialization upgrade cost is very high, then policies that influence the market openness are ineffective (i.e. the only equilibrium is the VS (F)). Moreover, if the trading cost is very low, then policies that affect the specialization upgrade cost are ineffective (i.e. the only equilibrium is VS) but can be calibrated to achieve the Pareto optimal equilibrium (VS (S) instead of VS (F)) by decreasing the specialization upgrade cost. On the contrary, in the presence of average specialization upgrade cost and high trading cost, the policies that affect $t$ and $\alpha$ are complementary. For example, VS (S) can be achieved by decreasing the specialization upgrade cost, by decreasing the trading cost or by a mix of both instruments. To sum up: since the risk of hold-up drives the vertical structure decision, when this risk is significant (i.e. in the presence of high specialization upgrade cost) or very low (i.e. in the presence of low trading cost) the two policies are independent of each other: $t$ only influences the decision to engage in international trade, and $\alpha$ only influences the specialization decision. Differently, when the risk of hold up is intermediate, the two policies are complementary.

European glocal policies There are several studies that analyse the European glocal policies and different successful examples that support our modelling strategy.

Recent publications identify possible instruments that regions can use to design efficient policies and strategies in order to increase the innovation process. ${ }^{34}$ According to these studies it is crucial that each region adopt a "strategic approach" by identifying its competitive advantages (i.e. by

\footnotetext{
${ }^{33}$ Note that in the open economy the $\alpha$ thresholds change with $\pi$ for $t$ sufficiently high.

${ }^{34}$ See the OECD (2013) "Regions and Innovation", the EU (2012) "Guide to Research and Innovation Strategies for Smart Specialization", and the EC Communication (COM 2010) "Regional Policy for smart growth in Europe 2020" All these studies identify several guidelines for European regions.
} 


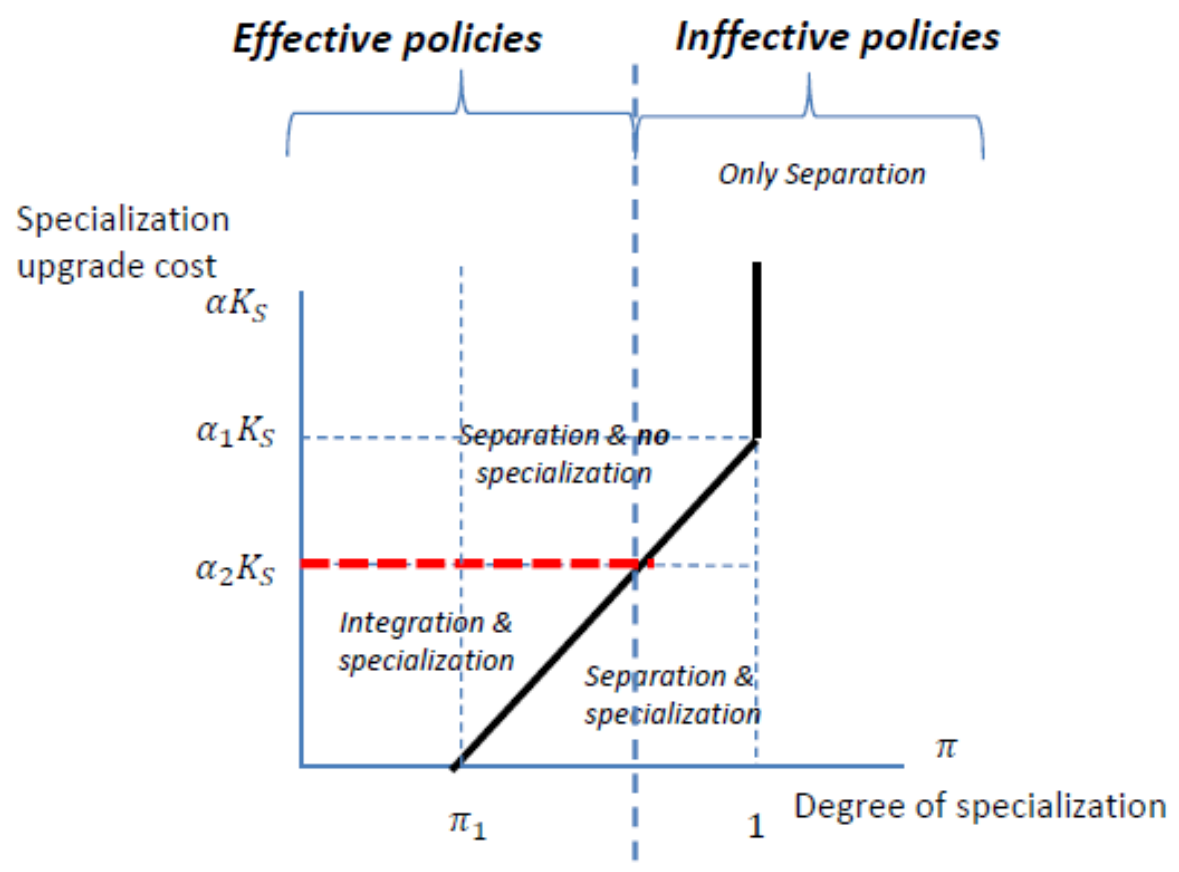

Figure 7: Effective/ineffective policies (closed economy)

a systematic comparison with other regions), so as to avoid a duplication of investments and a consequently loss of synergy potential between European regions. The European Cluster Observatory, the European Cluster Excellence initiative and the European Cluster Collaboration Platform can be a useful support for this initial step. Coherently with these theoretical guidelines, these studies report different examples from regions that have successfully used this strategic approach. A first example is given by the region of Toulouse which, starting by a smart specialization in aeronautics (Airbus valley), was able to extend entrepreneurial activities, higher education and research infrastructure to new areas (i.e. satellites and GPS technologies). Other two important examples are given by policies implemented in the Flanders and in Berlin. On one side Flanders had recently implemented the plan "Vlaanderen in Actie" (ViA) with the target to be one of the top five knowledge-intensive regions in Europe by 2020 by focusing on value chains, economic clusters, open innovation and grand projects. On the other side, in the 2001 the Brandenburg region decided to concentrate the innovative policies in Berlin. To implement these policies, the policy makers identified five specific fields of excellence (i.e., biotechnologies and medical technologies and pharmacy, energy technologies, ICT and new media, optical technologies, and transport system technologies) and four cross sectorial priorities (i.e., new materials, production and automation technology, cleantech, and security).

Another key element of these glocal policies is to increase the cooperation between public and 


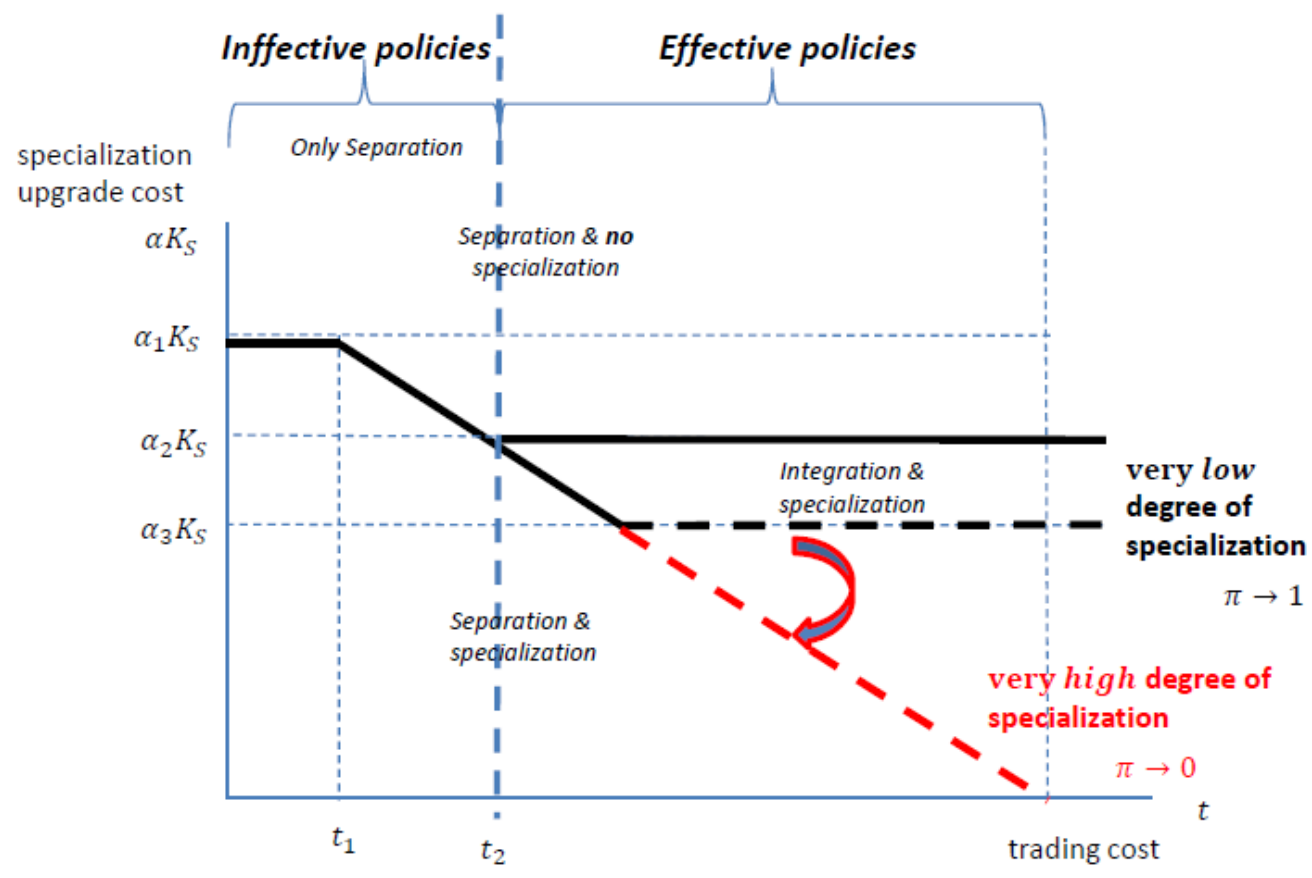

Figure 8: Effective/ineffective policies (open economy)

private sector. For instance there is the West Midlands Innovation Strategy project (1996), the Bavarian High Technology cluster policy $(1999)^{35}$ introduced with the goal to foster innovation and regional competitiveness of the Bavarian state through the provision of joint research facilities; and, in Japan, the Industrial Cluster Policy (ICP) based on the idea that cluster projects were more likely to achieve increased innovative outputs. ${ }^{36}$

Furthermore, these policies can help firms to acquire components (including knowledge embodied in these inputs) at affordable price. For example, Falck et al. (2010) found that firms were able to develop innovations at lower costs thanks to the Bavarian High Technology cluster policy. This lower cost of innovations can also be generated by a more efficient internationalization. For example, according to a Finnish survey (Ahvenharju et al 2006), public authorities can help the internationalization process of technological companies by supplying them with support services in these six areas: knowledge of international market and technology demand, strategy development for international $\mathrm{R} \& \mathrm{D}$ activities, identification and selection of partners, identification, selection and acquisition of

\footnotetext{
${ }^{35}$ Falck et al. (2010) evaluate econometrically this Bavarian High Technology cluster policy following a two part strategy. They first compare the innovation performance of firms in target industries with similar firms in other German states, before and after the policy was introduced.

${ }^{36}$ Nishimura and Okamuro (2011) found that "participating in a cluster especially one in which a core national university is a member, is likely to provide access to increased knowledge flows, facilitate transfer of tacit knowledge and reduce uncertainty, through better access to local communication and collaboration with other partners".
} 
technology, skilled personnel, funding for international core, close-to-market and supporting R\&D.

These policies are becoming more relevant as the European Research Area is advancing. In particular, in the European context, the deployment of Key Enabling Technologies (KETs) becomes a crucial element of any smart specialization strategy. These smart specialization strategies can help each region to address this gap between innovation and commercial application. An example of the successful use of KETs is the Slovenian automotive sector which has developed specialised products to supply the main European car manufacturers (EU, 2012).

We conjecture that many other successes will occur in the next future given these policies, that actually attenuate the hold-up problem thanks to a risk-sharing effect.

\section{Conclusion}

We have analysed how the policy maker can influence firms' vertical integration decisions at different levels: by manipulating the input specialization costs (local, regional level), the integration cost and/or the trading costs (national, international level).

Our contribution is threefold. First, we have introduced different degrees of specialization. This specialization heterogeneity is relevant because it affects the signficance of the hold-up problem and in turn the vertical organization as well as the specialization decisions. Secondly, based on the increasing empirical evidence, we have introduced the idea that the sunk cost of specialization can be manipulated by the policy maker through several channels: basic research, specific public IT investments, public research structures and postgraduate courses that focuses on specific specialized inputs, fiscal policies that reduce the costs of specialization, etc. All these policies can reduce the cost of specialization for a single firm or for a particular cluster and consequently influence the final equilibrium. Thirdly, we have analysed the role of trade liberalization. The international openness affects firms' vertical integration decisions by mitigating the hold-up problem (i.e. by rising market thickness).

At equilibrium the vertical structure and the specialization decision depend on the specialization costs, the integration costs and the trade costs. We have characterized the conditions under which the policies are effective in achieving a particular vertical organization equilibrium. In the closed economy the degree of input specialization and the cost of this specialization are crucial in order to implement policies that influence the firms'/clusters' decisions. This scenario changes in the open economy, where the presence of highly specialized inputs becomes less and less crucial to ensure the success of these policies.

As for future research, it would be interesting to test our results from an empirical point of view. More precisely, we should consider sector level data on: the vertical organization, the importance of the specialized input with respect to nonspecialized inputs (measured for instance by the relative amount of resources devoted to the production of specialized vs nonspecilized inputs), the different degrees of specialization, for instance how much an input has to be modified to customize an output, ${ }^{37}$

\footnotetext{
${ }^{37}$ We could also consider the Pavitt taxonomy.
} 
the openness to international trade. Finally regional/national data on policies aiming at affecting trade openness and specialization costs. The theoretical statements to test regard the effectiveness of glocal policies on firms' vertical structure under different degrees of trade openness: does the effectiveness of these policies changes across sectors depending on the importance of for instance EU trade partners versus extra-EU trade partners?

Note also that our approach allows us to consider a number of further issues. First, as studied, among others, by Ornelas and Turner (2008) trade liberalization affects vertical multinational integration, that is the possibility of integration with a foreign firm (foreign direct investment, FDI). Second, institutions may act either in a symmetric or an asymmetric way in each region, thus affecting in non trivial ways the integration/specialization decisions. Further, this approach emphasizes a relationship between the previously described regional policies and FDI. This opens the door to potential strategic policies to attract FDI that, as far as we know, are not deeply studied in the literature. Indeed, there is a vast literature on trade, FDI, and the organization of firms (see the recent survey by Helpman (2006)) as well as a literature on regions' competition to attract FDI. The main focus of the latter being fiscal incentives and infrastructure policy decisions (see Dembour (2008)). 


\section{$7 \quad$ Appendix}

\subsection{Glossary}

We here report the definitions used throughout the paper.

- $\alpha K_{S}$ : specialization upgrade cost

- $\Delta=R_{j j}-e_{j j}$ : (gross) specialization upgrade gain

- $\Delta-L$ : specialization upgrade gain hold-up free, or net specialization upgrade gain.

- $\varepsilon=e_{j j}-e_{j-j}$ : fitting gain for a flexible input

- $R_{k k}-0$ : fitting gain for a specialized input; $R_{k k}-\pi R_{k k}$

- $R_{j j}-\varepsilon=R_{j j}-0-\left(e_{j j}-e_{j-j}\right)$ : fitting gap.

- $\Delta+\varepsilon=R_{j j}-e_{j j}+\left(e j j-e_{j-j}\right)=R_{j j}-e_{j-j}$ : difference between the max hold-up in case of specialization and the min hold-up in case of flexible inputs.

- VI (F): vertical integration with a flexible input

- VI (S): vertical integration with a specialized input

- VS (F): vertical separation with a flexible input

- VS (S): vertical separation with a specialized input

\subsection{Market stage}

In this Section we analyse the market stage, that is the price setting in the closed and in the open economy.

Case VS (F) In order to find the equilibrium price for the flexible input produced by firm $U_{j}$, we first detail the willingness to pay of the D firms for this input (from which we can infer the maximal possible price) and then we analyse the selling possibilities of the $U$ firms (from which we can infer the minimal price that $U_{j}$ is willing to accept, that is its outside option). The equilibrium price is determined by $U_{j}$ 's maximal outside option, that coincides with the second best offer. We assume that if firm $D_{-j}$ offers the same price as firm $D_{j}$, then $U_{j}$ will sell to $D_{j}$.

1) $D_{j}$ is willing to pay a price such that $P_{j F} \in\left[0, e_{j j}\right]$

2) $D_{-j}$ is willing to pay a price such that $P_{-j F} \in\left[0, e_{j-j}\right]$

3) $D_{j}^{*}$ is willing to pay a price such that $P_{j F}^{*} \in\left[0, e_{j j}^{*}-t\right]$

4) $D_{-j}^{*}$ is willing to pay a price such that $P_{-j F}^{*} \in\left[0, e_{j-j}^{*}-t\right]$

5) $D_{N+h}$ is willing to pay a price such that $P_{N+h F} \in\left[0, \pi e_{k k}+(1-\pi) e_{k-k}\right]$

6) $D_{N+h}^{*}$ is willing to pay a price such that $P_{N+h F}^{*} \in\left[0,\left(\pi e_{k k}^{*}+(1-\pi) e_{k-k}^{*}\right)-t\right]$ 
$U_{j}$ for $j=i$ can sell to $(1,2)$ in the closed economy and to (1-4) in the open economy; $U_{j}$ for $j=k$ (special firms) can sell to $(1,2,5)$ in the closed economy and to (1-6) in the open economy.

- $U_{j}$ : in the closed economy, the outside option is $e_{i j}$. Then $D_{i}$ will offer a price equal to $e_{i j}$ that excludes from the market the other competitors: the equilibrium price is therefore

$$
P_{i F}=e_{i j}
$$

In the open economy, the outside option is $\max \left\{e_{i j}, e_{i i}^{*}-t, e_{i j}^{*}-t\right\}=\max \left\{e_{i j}, e_{i i}^{*}-t\right\}$. The equilibrium price is then

$$
P_{i F}^{*}=\left\{\begin{array}{c}
e_{i j}=P_{i F} \text { if } t>e_{i i}-e_{i j} \equiv \varepsilon \\
e_{i i}-t>P_{i F} \text { if } t<\varepsilon
\end{array} .\right.
$$

- $U_{k}$ : in the closed economy, the outside option is $\max \left\{e_{k j}, \pi e_{k k}+(1-\pi) e_{k j}\right\}=\pi e_{k k}+(1-\pi) e_{k j}$.

The equilibrium price is therefore

$$
P_{k F}=\pi e_{k k}+(1-\pi) e_{k j}>P_{i F} .
$$

In the open economy, the outside option is $\max \left\{e_{k j}, e_{k j}^{*}-t, e_{k k}^{*}-t, \pi e_{k k}+(1-\pi) e_{k j},\left(\pi e_{k k}^{*}+(1-\pi) e_{k k}^{*}\right)-\right.$ $t\}=\max \left\{e_{k k}^{*}-t, \pi e_{k k}+(1-\pi) e_{k j}\right\}$. The equilibrium price is then

$$
P_{k F}^{*}=\left\{\begin{array}{c}
\pi e_{k k}+(1-\pi) e_{k j}=P_{k F} \text { if } t>(1-\pi) \varepsilon \\
e_{k k}^{*}-t>P_{i F} \text { if } t<(1-\pi) \varepsilon
\end{array} .\right.
$$

Case VS (S) In order to find the equilibrium price for the specialized input produced by firm $U_{j}$, we first detail the willingness to pay of the $\mathrm{D}$ firms for this input and then we analyse the selling possibilities of the $\mathrm{U}$ firms. The equilibrium price is determined by $U_{j}$ 's maximal outside option, that coincides with the second best offer. We assume that if firm $D_{-j}$ offers the same price as firm $D_{j}$, then $U_{j}$ will sell to $D_{j}$.

1) $D_{j}$ is willing to pay a price such that $P_{j S} \in\left[0, R_{j j}\right]$

2) $D_{-j}$ is willing to pay a price such that $P_{-j S}=0$

3) $D_{j}^{*}$ is willing to pay a price such that $P_{j S}^{*} \in\left[0, R_{j j}^{*}-t\right]$

4) $D_{-j}^{*}$ is willing to pay a price such that $P_{-j S}^{*}=0$

5) $D_{N+h}$ is willing to pay a price such that $P_{N+h, S} \in\left[0, \pi R_{k k}\right]$

6) $D_{N+h}^{*}$ is willing to pay a price such that $P_{N+h, S}^{*} \in\left[0, \pi R_{k k}^{*}-t\right]$

$U_{j}$ for $j=i$ can sell to $(1)$ in the closed economy and to $(1,3)$ in the open economy. $U_{j}$ for $j=k$ can sell to $(1$ and 5$)$ in the closed economy and to $(1,3,5,6)$ in open economy.

- $U_{i}$ : in the closed economy, the outside option is 0 . Then, the equilibrium price is

$$
P_{i S}=0 .
$$

In the open economy, the outside option is $R_{i i}^{*}-t$. The equilibrium price is then

$$
P_{i S}^{*}=R_{i i}^{*}-t>P_{i S} .
$$


- $U_{k}$ : in the closed economy, the outside option is $\pi R_{k k}$. The equilibrium price is therefore

$$
P_{k S}=\pi R_{k k}>P_{i S}
$$

In the open economy, the outside option is $\max \left\{R_{k k}^{*}-t, \pi R_{k k}, \pi R_{k k}^{*}-t\right\}=\max \left\{R_{k k}^{*}-t, \pi R_{k k}\right\}$. The equilibrium price is then

$$
P_{k S}^{*}=\left\{\begin{array}{c}
\pi R_{k k}=P_{k S} \text { if } t>(1-\pi) R_{k k}^{*} \\
R_{k k}^{*}-t<P_{k S} \text { if } t<(1-\pi) R_{k k}^{*}
\end{array} .\right.
$$

Case VI Clearly, whenever firms decide to merge, there is no market price setting because the input is transferred at its marginal cost.

Summing up in the closed economy market stage, there are the following four sub-games with associated payoffs.

1. Vertical separation, flexible input: VS $(\mathrm{F})$. The equilibrium bid by $D_{i}$ to firm $U_{i}$ is $P_{i F}=$ $e_{i j}>0$ and so $U_{i}$ gets a payoff equal to $e_{i j}-K_{F}$ and $D_{i}$ gets a payoff equal to $e_{i i}-e_{i j}$. The equilibrium bid by $D_{k}$ to firm $U_{k}$ is $P_{k F}=\pi e_{k k}+(1-\pi) e_{k j}$ and so $U_{k}$ gets a payoff equal to $\pi e_{k k}+(1-\pi) e_{k j}-K_{F}$ and $D_{k}$ gets a payoff equal to $e_{k k}-\pi e_{k k}-(1-\pi) e_{k j}=$ $(1-\pi)\left(e_{k k}-e_{k j}\right)$. Note that $e_{k k}=e_{i i}$ and $e_{k j}=e_{i j}$.

2. Vertical separation, specialized input: VS (S). The equilibrium bid by $D_{i}$ to $U_{i}$ is $P_{i S}=0$ and so $U_{i}$ gets $-K_{S}$ and $D_{i}$ gets $R_{i i}-0$. The equilibrium bid by $D_{k}$ to $U_{k}$ is $P_{k S}=\pi R_{k k}$ and so $U_{k}$ gets $\pi R_{k k}-K_{S}$ and $D_{k}$ gets $R_{k k}-\pi R_{k k}$. Note that $R_{k k}=R_{i i}$ and $R_{k j}=R_{i j}$.

3. Vertical integration, flexible input: VI (F). The merger $U_{j}-D_{j}$ gets $e_{j j}-L-K_{F}, \forall j=i, k$.

4. Vertical integration, specialized input: VI (S). The merger gets $R_{j j}-L-K_{S}, \forall j=i, k$.

Summing up in the open economy market stage, there are four sub-games.

1. Vertical separation, flexible input: VS (F). The equilibrium price received by firm $U_{i}$ depends on the level of trade cost $t$ :

$$
P_{i F}^{*}=\left\{\begin{array}{l}
e_{i j} \text { if } t>\varepsilon \\
e_{i i}-t \text { else }
\end{array}\right.
$$

so that $U_{i}$ gets a payoff equal to either $e_{i j}-K_{F}$ or $e_{i i}-t-K_{F}$ and $D_{i}$ gets a payoff equal to either $e_{i i}-e_{i j}$ or $t$. The equilibrium price for the special firm $U_{k}$ :

$$
P_{k F}^{*}=\left\{\begin{array}{c}
\pi e_{k k}+(1-\pi) e_{k j} \text { if } t>\varepsilon(1-\pi) \\
e_{k k}-t \text { else }
\end{array}\right.
$$

so that $U_{k}$ gets a payoff equal to either $\pi e_{k k}+(1-\pi) e_{k j}-K_{F}$ or $e_{k k}-t-K_{F}$ and $D_{k}$ gets a payoff equal to either $e_{k k}-\pi e_{k k}-(1-\pi) e_{k j}=(1-\pi) \varepsilon$ or $t$. 
2. Vertical separation, specialized input: VS (S). The equilibrium price for a $i$ firm is $P_{i S}^{*}=R_{i i}-t$, so that $U_{i}$ gets $R_{i i}-t-K_{S}$ and $D_{i}$ gets $t$. Whereas the equilibrium price for the special firm $U_{k}$ is:

$$
P_{k S}^{*}=\left\{\begin{array}{c}
\pi R_{k k} \text { if } t>R_{k k}(1-\pi) \\
R_{k k}-t \text { else }
\end{array}\right.
$$

so that $U_{k}$ gets a payoff equal to either $\pi R_{k k}-K_{F}$ or $R_{k k}-t-K_{F}$ and $D_{k}$ gets a payoff equal to either $R_{k k}-\pi R_{k k}-(1-\pi) R_{k j}=(1-\pi)\left(R_{k k}-R_{k j}\right)$ or $t$.

3. Vertical integration, flexible input: VI (F). The merger $U_{j}-D_{j}$ gets $e_{j j}-\min \left\{L^{1}, L^{2}\right\}-K_{F}$, $\forall j=i, k$.

4. Vertical integration, specialized input: VI (S). The merger gets $R_{j j}-\min \left\{L^{1}, L^{2}\right\}-K_{S}$, $\forall j=i, k$.

\subsection{Production stage}

\subsubsection{Proof of Lemma 1}

Given the market stage, the proof of Lemma 1 comes from the comparison of the proper payoffs.

(i) Under VS, $U_{i}$ obtains: $P_{i F}-K_{F}=e_{i j}-K_{F}$ for a flexible input and $P_{i S}-K_{S}=0-K_{S}$ for a specialized input, therefore $e_{i j}-K_{F}>-K_{S}$, always holds; $U_{k}$, instead, obtains: $P_{k F}-K_{F}=$ $\pi e_{k k}+(1-\pi) e_{k j}-K_{F}$ for a flexible input and $P_{k S}-K_{S}=\pi R_{k k}-K_{S}$ for a specialized input, therefore the comparison becomes:

$$
\begin{aligned}
\pi e_{k k}+(1-\pi) e_{k j}-K_{F} & >\pi R_{k k}-K_{S} \\
& \Longleftrightarrow \alpha K_{S}+e_{k j}>\pi\left(R_{k k}-e_{k k}+e_{k j}\right) \\
& \Longleftrightarrow \pi<\pi^{F} .
\end{aligned}
$$

(ii) The VI entity obtains: $e_{i i}-L-K_{F}$ for a flexible input and $R_{i i}-L-K_{S}$ for a specialized input, therefore:

$$
\begin{aligned}
e_{i i}-L-K_{F} & >R_{i i}-L-K_{S} \\
& \Longleftrightarrow \alpha K_{S}>\Delta
\end{aligned}
$$

\subsubsection{Proof of Lemma 3}

(i) Comparing the payoff from producing a flexible $(\mathrm{F})$ or a specialized (S) input under vertical separation for the $i$ firms, we obtain that VS (F) prevails over VS (S) for firms $U_{i}$ iff:

$$
\begin{gathered}
P_{i F}^{*}-K_{F}>P_{i S}^{*}-K_{S} \\
\Longleftrightarrow \max \left\{e_{i j}, e_{i i}-t\right\}-K_{F}>R_{i i}-t-K_{S} \\
\Longleftrightarrow \alpha K_{S}>R_{i i}-t-\max \left\{e_{i j}, e_{i i}-t\right\} .
\end{gathered}
$$

Therefore, we distinguish the two following cases. 
1. $e_{i j}>e_{i i}-t \Longleftrightarrow t>\varepsilon$, then the above inequality becomes: $\alpha K_{S}>R_{i i}-t-e_{i j}=\Delta+\varepsilon-t$.

2. $e_{i j}<e_{i i}-t \Longleftrightarrow t<\varepsilon$, then the above inequality becomes: $\alpha K_{S}>\Delta$.

Under vertical separation we obtain that VS (F) prevails over VS (S) for firms $U_{k}$ iff:

$$
\begin{gathered}
P_{k F}^{*}-K_{F}>P_{k S}^{*}-K_{S} \\
\Longleftrightarrow \max \left\{\pi e_{k k}+(1-\pi) e_{k j}, e_{k k}^{*}-t\right\}-K_{F}>\max \left\{\pi R_{k k}, R_{k k}^{*}-t\right\}-K_{S} \\
\Longleftrightarrow \alpha K_{S}>\max \left\{\pi R_{k k}, R_{k k}^{*}-t\right\}-\max \left\{\pi e_{k k}+(1-\pi) e_{k j}, e_{k k}^{*}-t\right\}
\end{gathered}
$$

The production choice of the special firms $U_{k}$ also depends on $t$ :

1. $t>(1-\pi) R_{k k}$ : VS (F) is preferred to VS (S) iff

$$
\begin{gathered}
P_{k F}^{*}-K_{F}>P_{k S}^{*}-K_{S} \\
\Longleftrightarrow\left(\pi e_{k k}+(1-\pi) e_{k j}\right)-K_{F}>\left(\pi R_{k k}\right)-K_{S} \\
\Longleftrightarrow \alpha K_{S}>\Delta+(1-\pi)\left(\varepsilon-R_{k k}\right)
\end{gathered}
$$

2. $t \in\left((1-\pi) \varepsilon,(1-\pi) R_{k k}\right)$ : VS (F) is preferred to VS (S) iff

$$
\begin{gathered}
P_{k F}^{*}-K_{F}>P_{k S}^{*}-K_{S} \\
\Longleftrightarrow\left(\pi e_{k k}+(1-\pi) e_{k j}\right)-K_{F}>\left(R_{k k}-t\right)-K_{S} \\
\Longleftrightarrow \alpha K_{S}>\Delta+(1-\pi) \varepsilon-t
\end{gathered}
$$

3. $t<(1-\pi) \varepsilon$ : VS $(\mathrm{F})$ is preferred to VS (S) iff

$$
\begin{gathered}
P_{k F}^{*}-K_{F}>P_{k S}^{*}-K_{S} \\
\Longleftrightarrow\left(e_{i i}-t\right)-K_{F}>\left(R_{k k}-t\right)-K_{S} \\
\Longleftrightarrow \alpha K_{S}>\Delta
\end{gathered}
$$

(ii) Comparing the payoff from producing a flexible $(\mathrm{F})$ or a specialized $(\mathrm{S})$ input under vertical integration, we obtain the following comparison for both $i$ and $k$ firms:

$$
\begin{gathered}
e_{j j}-\min \left\{L^{1}, L^{2}\right\}-K_{F}>R_{j j}-\min \left\{L^{1}, L^{2}\right\}-K_{S} \\
\Longleftrightarrow \alpha K_{S}>R_{j j}-e_{j j}=\Delta .
\end{gathered}
$$

\subsection{Merger stage}

\subsubsection{Proof of Lemma 2}

(i) From the production stage we know that, under VS, $U_{k}$ chooses $\mathrm{F}$ rather than $\mathrm{S}$ iff $\pi<\pi^{F}$, therefore we compare the joint profits of $U_{k}$ and $D_{k}$ under VS with the profit of the VI entity. When $\pi<\pi^{F}$,

$$
P_{k F}-K_{F}+e_{k k}-P_{k F}=e_{k k}-K_{F}>\left\{\begin{array}{l}
e_{k k}-L-K_{F} \text { if } \alpha K_{S}>\Delta \\
R_{k k}-L-K_{S} \text { if } \alpha K_{S}<\Delta
\end{array}\right.
$$


If $\alpha K_{S}>\Delta$, VI never occurs because

$$
\begin{aligned}
e_{k k}-K_{F} & >e_{k k}-L-K_{F} \\
& \Longleftrightarrow L>0, \text { always }
\end{aligned}
$$

If $\alpha K_{S}<\Delta$, VS (F) rather than VI (S) occurs iff:

$$
\begin{aligned}
e_{k k}-K_{F} & >R_{k k}-L-K_{S} \\
& \Longleftrightarrow \Delta-L<\alpha K_{S}
\end{aligned}
$$

When $\pi>\pi^{F}$, we have that $\alpha K_{S}>\Delta$ never occurs because this case implies $\pi^{F}>1$. Then, the comparison VS $(\mathrm{S})$ versus VI $(\mathrm{S})$ reduces to:

$$
\begin{aligned}
P_{k S}-K_{S}+R_{k k}-P_{k S} & =R_{k k}-K_{S}>R_{k k}-L-K_{S} \\
& \Longleftrightarrow L>0, \text { always. }
\end{aligned}
$$

(ii) From the production stage we know that, under VS, $U_{i}$ always chooses $\mathrm{F}$ therefore we compare the joint profits of $U_{i}$ and $D_{i}$ under VS (F) and the profit of the VI entity:

$$
P_{i F}-K_{F}+e_{i i}-P_{i F}=e_{i i}-K_{F}>\left\{\begin{array}{l}
e_{i i}-L-K_{F} \text { if } \alpha K_{S}>\Delta \\
R_{i i}-L-K_{S} \text { if } \alpha K_{S}<\Delta
\end{array}\right.
$$

If $\alpha K_{S}>\Delta$, VI never occurs and so VS (F) prevails, because

$$
\begin{aligned}
e_{i i}-K_{F} & >e_{i i}-L-K_{F} \\
& \Longleftrightarrow L>0, \text { always }
\end{aligned}
$$

If $\alpha K_{S}<\Delta$, VS (F) rather than VI (S) occurs iff:

$$
\begin{aligned}
e_{i i}-K_{F} & >R_{i i}-L-K_{S} \\
& \Longleftrightarrow \alpha K_{S}>\Delta-L
\end{aligned}
$$

Then, for $\alpha K_{S} \in(\Delta-L, \Delta)$, VS (F) prevails; for $\alpha K_{S}<\Delta-L$, VI (S) prevails.

\subsubsection{Proof of Lemma 4}

(i) From the production stage we know that, under VS, $U_{k}$ chooses $\mathrm{F}$ rather than $\mathrm{S}$ if

Case $1 t>(1-\pi) R_{k k} \cup \alpha K_{S}>\Delta+(1-\pi)\left(\varepsilon-R_{k k}\right)$

Case $2 t \in\left((1-\pi) \varepsilon,(1-\pi) R_{k k}\right) \cup \alpha K_{S}>\Delta+(1-\pi) \varepsilon-t$

Case $3 t<(1-\pi) \varepsilon \cup \alpha K_{S}>\Delta$, and, $U_{k}$ chooses $\mathrm{S}$ rather than $\mathrm{F}$ if

Case $4 t>(1-\pi) R_{k k} \cup \alpha K_{S}<\Delta+(1-\pi)\left(\varepsilon-R_{k k}\right)$ 
Case $5 t \in\left((1-\pi) \varepsilon,(1-\pi) R_{k k}\right) \cup \alpha K_{S}<\Delta+(1-\pi) \varepsilon-t$

Case $6 t<(1-\pi) \varepsilon \cup \alpha K_{S}<\Delta$.

Moreover, from the production stage we know that the VI entity $U_{k}$ and $D_{k}$ chooses VI (F) if $\alpha K_{S}>\Delta$ and VI (S) if $\alpha K_{S}<\Delta$.

When we compare the profit of the VI entity with the joint profits of $U_{k}$ and $D_{k}$ under VS, three different scenarios arise:

a VI $(\mathrm{F})>\operatorname{VS}(\mathrm{F})[$ Case 3$]$

$$
\begin{gathered}
e_{k k}-\min \left\{L^{1}, L^{2}\right\}-K_{F}>e_{k k}-K_{F} \\
\Longleftrightarrow-\min \left\{L^{1}, L^{2}\right\}>0 \text { NEVER }
\end{gathered}
$$

b VI $(\mathrm{S})>\operatorname{VS}(\mathrm{F})[$ Cases 1,2$]$

$$
\begin{gathered}
R_{k k}-\min \left\{L^{1}, L^{2}\right\}-K_{S}>e_{k k}-K_{F} \\
\Longleftrightarrow \Delta-\min \left\{L^{1}, L^{2}\right\}>\alpha K_{S}
\end{gathered}
$$

c VI $(\mathrm{S})>\operatorname{VS}(\mathrm{S})[$ Cases $4,5,6]$

$$
\begin{gathered}
R_{k k}-\min \left\{L^{1}, L^{2}\right\}-K_{S}>R_{k k}-K_{S} \\
\Longleftrightarrow-\min \left\{L^{1}, L^{2}\right\}>0 \mathrm{NEVER}
\end{gathered}
$$

(ii) From the production stage we know that VS (F) prevails over VS (S) for firm $U_{i}$ if

Case $1 t>\varepsilon \cup \alpha K_{S}>\Delta+\varepsilon-t$

Case $2 t<\varepsilon \cup \alpha K_{S}>\Delta$.

and, VS (S) prevails over VS (F) if

Case $3 t>\varepsilon \cup \alpha K_{S}<\Delta+\varepsilon-t$

Case $4 t<\varepsilon \cup \alpha K_{S}<\Delta$.

Moreover, from the production stage we know that the VI entity $U_{i}$ and $D_{i}$ chooses VI (F) if $\alpha K_{S}>\Delta$ and VI (S) if $\alpha K_{S}<\Delta$.

When we compare the profit of the VI entity with the joint profits of $U_{i}$ and $D_{i}$ under VS, three different scenarios arise:

a $\quad \mathrm{VI}(\mathrm{F})>\mathrm{VS}(\mathrm{F})[$ Cases 1, 2]

$$
\begin{aligned}
e_{i i}-\min & \left\{L^{1}, L^{2}\right\}-K_{F}>e_{i i}-K_{F} \\
& -\min \left\{L^{1}, L^{2}\right\}>0 \mathrm{NEVER}
\end{aligned}
$$


b VI $(\mathrm{S})>\operatorname{VS}(\mathrm{F})\left[t>\varepsilon \cup \alpha K_{S} \in[\Delta+\varepsilon-t, \Delta]\right]$

$$
\begin{gathered}
R_{i i}-\min \left\{L^{1}, L^{2}\right\}-K_{S}>e_{k k}-K_{F} \\
\Delta-\min \left\{L^{1}, L^{2}\right\}>\alpha K_{S}
\end{gathered}
$$

c $\quad$ VI $(\mathrm{S})>\operatorname{VS}(\mathrm{S})[$ Cases 3,4$]$

$$
\begin{aligned}
R_{i i}-\min & \left\{L^{1}, L^{2}\right\}-K_{S}>R_{i i}-K_{S} \\
-\min \left\{L^{1}, L^{2}\right\} & >0 \mathrm{NEVER}
\end{aligned}
$$

Note that the special firms choose VI (S) only if $\Delta-\min \left\{L^{1}, L^{2}\right\}>\Delta+(1-\pi)\left(\varepsilon-R_{k k}\right) \Longleftrightarrow$ $\min \left\{L^{1}, L^{2}\right\}<(1-\pi)\left(R_{k k}-\varepsilon\right)$. Indeed, for larger values of $\min \left\{L^{1}, L^{2}\right\}$, the interval $[\max \{\Delta+(1-\pi) \varepsilon-t, \Delta+$ is empty. The intuition is that when the organization costs of vertical integration are too large, vertical integration is not profitable. Note that the lower is $\pi$, the wider is this interval. Also the interval where VI (S) occurs for the $i$ firms is always wider than the corresponding interval for the $k$ firms (except for the trivial case $\pi=0$ ).

\subsection{Equilibrium}

\subsubsection{Proof of Proposition 1 and proof of Corollary 2}

These proofs follow from the proof of Lemma 2. The following table summarizes these results, that is our closed economy equilibrium:

\begin{tabular}{|l|l|l|l|}
\hline At Equilibrium & \multicolumn{3}{|l|}{$k$ Firms } \\
\hline & $\pi<\pi^{F}$ & $\pi>\pi^{F}$ & \\
\hline$\alpha K_{S}<\Delta-L$ & VI (S) & VS (S) & VI (S) \\
\hline$\alpha K_{S} \in(\Delta-L, \Delta)$ & VS (F) & VS (S) & VS (F) \\
\hline$\alpha K_{S}>\Delta$ & VS (F) & VS (F) \\
\hline
\end{tabular}

As explained in the text, Figure 2 describes the equilibrium behaviors of firms' in the closed economy. Figure $2 \mathrm{~b}$ deserves a more detailed explanation. It displays the special firms' behaviors: with respect to Figure 2a, we get a further relevant threshold, $\pi^{F}\left(\alpha K_{S}\right)$, increasing with $\alpha K_{S}$. Consider the extreme case $\alpha K_{S}=0$ so that $\pi^{F}(0)=\frac{e_{k j}}{\Delta+e_{k j}}$. Defining

$$
\varepsilon \equiv e_{k k}-e_{k j}
$$

as the fitting gain for a flexible input and $R_{k k}-0$, the fitting gain for a specialized input, we can rearrange $\Delta+e_{k j}$ as $\Delta+e_{k j}=R_{k k}-\varepsilon=R_{k k}-0-\left(e_{k k}-e_{k j}\right)$, that we call the fitting gap. Note that $\pi^{F}(0)$ decreases with the fitting gap: the lower is the fitting gap, the smaller is the area where VS (S) occurs. Moreover, as $\Delta$ decreases ( $\Delta \rightarrow L$ for instance), the area VS (F) becomes larger at the expense of the area VI (S) and VS (S). In the limit $\Delta \rightarrow 0$ then $\pi^{F}(0) \rightarrow 1$ and $\Delta-L$ becomes negative, so that all the specialization area collapses to zero. Thus, ceteris paribus, the difference between the firms $U_{i}$ and $U_{k}$ depend on $\Delta$. In particular, this difference is relevant for high enough 
values of $\Delta$ that represents the (gross) upgrade gain: the larger is this gain from specialization, the higher is the loss incurred in case of hold-up. Indeed, an increase in $\Delta$ implies for both types of firms an increase of specialization. However, for firms $U_{i}$, the higher is $\Delta$ the higher is the incentive to vertically integrate (i.e., the insurance area against hold up, VI (S), increases). In contrast, an increase of $\Delta$ has a less trivial effect for the special firms: it certainly implies an increase of the area VS (S) but a priori it is not clear whether the area VI (S) also increases or rather decreases. Direct computations show that as $\Delta$ increases, areas VI (S) and VS (S) increase at the expense of VS (F).

\subsubsection{Proof of Proposition 2 and proof of Corollary 3}

These proofs follow from the proof of Lemma 4. Let us rewrite the cases identified in Lemma 4 as function of $\pi$. From the production stage we know that, under VS, $U_{k}$ chooses $\mathrm{F}$ rather than $\mathrm{S}$ iff $\alpha K_{S}>$ intermediate $\left\{\Delta, \Delta+(1-\pi) \varepsilon-t, \Delta+(1-\pi)\left(\varepsilon-R_{k k}\right)\right\}$, that is iff:

1. $\pi>1-\frac{t}{R_{k k}} \cup \alpha K_{S}>\Delta-\left(R_{k k}-\varepsilon\right)(1-\pi)$

2. $\pi \in\left[1-\frac{t}{\varepsilon}, 1-\frac{t}{R_{k k}}\right] \cup \alpha K_{S}>\Delta+(\varepsilon-t)-\pi \varepsilon=\Delta+(1-\pi) \varepsilon-t$

3. $\pi<1-\frac{t}{\varepsilon} \cup \alpha K_{S}>\Delta$.

The following table summarizes our results, that is our open economy equilibrium:

\begin{tabular}{|c|c|c|c|c|}
\hline At Equilibrium & \multicolumn{4}{|l|}{$k$ Firms } \\
\hline & $\pi<1-\frac{t}{\varepsilon}$ & $\pi \in$ & $1-\frac{t}{\varepsilon}, 1-\frac{t}{R_{k k}}$ & $\pi>1-\frac{t}{R_{k k}}$ \\
\hline$\alpha K_{S}>\Delta$ & \multicolumn{4}{|c|}{$\mathrm{VS}(\mathrm{F})$} \\
\hline$\alpha K_{S} \in\left(\Delta+\max \left\{(1-\pi) \varepsilon-t,(1-\pi)\left(\varepsilon-R_{k k}\right)\right\}, \Delta\right)$ & $\mathrm{VS}(\mathrm{F})$ & & \multicolumn{2}{|c|}{$\begin{array}{c}\text { if } \alpha K_{S}<\Delta-\min (\mathrm{S}) \\
\operatorname{VS}(\mathrm{F}) \\
\text { if } \alpha K_{S}>\Delta-\min \left\{L^{1}, L^{2}\right\}\end{array}$} \\
\hline$\alpha K_{S}<\Delta+\max \left\{(1-\pi) \varepsilon-t,(1-\pi)\left(\varepsilon-R_{k k}\right)\right\}$ & $\mathrm{VS}(\mathrm{F})$ & \multicolumn{3}{|c|}{$\mathrm{VS}(\mathrm{F})$} \\
\hline & \multicolumn{4}{|l|}{$i$ Firms } \\
\hline & $t<\varepsilon$ & \multicolumn{3}{|c|}{$t>\varepsilon$} \\
\hline$\alpha K_{S}>\Delta$ & $\mathrm{VS}(\mathrm{F})$ & \multicolumn{3}{|c|}{$\mathrm{VS}(\mathrm{F})$} \\
\hline$\alpha K_{S} \in(\Delta+\min \{\varepsilon-t, 0\}, \Delta)$ & $\nexists$ & \multicolumn{3}{|c|}{$\begin{array}{c}\mathrm{VI}(\mathrm{S}) \\
\text { if } \alpha K_{S}<\Delta-\min \left\{L^{1}, L^{2}\right\} \\
\operatorname{VS}(\mathrm{F}) \\
\text { if } \alpha K_{S}>\Delta-\min \left\{L^{1}, L^{2}\right\}\end{array}$} \\
\hline$\alpha K_{S}<\Delta+\min \{\varepsilon-t, 0\}$ & $\mathrm{VS}(\mathrm{S})$ & \multicolumn{3}{|c|}{$\mathrm{VS}(\mathrm{S})$} \\
\hline
\end{tabular}

\section{References}

[1] Acemoglu, D. , Johnson S. and Mitton T. (2009), Determinants of vertical integration: finance contracts and regulation, Journal of Finance 63, pp. 1251-1288.

[2] Ahmadjian, C.L., Lincoln, J.R., 2001. Keiretsu, governance, and learning: case studies in change from the Japanese automotive industry. Organization Science 12, 683- 701. 
[3] Ahvenharju, S., M. Syrjanen and M. Hjelt, 2006, International R\&D in High Growth SMEs. Implications to Innovation Policy, Helsinki, Gaia Group Oy.

[4] Alfaro L., P. Conconi, H. Fadinger, A. F. Newman , 2010. Do Prices Determine Vertical Integration? NBER Working Paper No. 16118.

[5] Antràs, P, 2003. Firms, Contracts, And Trade Structure, The Quarterly Journal of Economics", vol. 118(4), pages 1375-1418.

[6] Atalay, E., A. Hortaçsu, and C. Syverson. 2014. Vertical Integration and Input Flows. American Economic Review, 104(4): 1120-48.

[7] Bonaccorsi, A., Giuri, P., 2001. The long-term evolution of vertically-related industries. International Journal of Industrial Organization 19, 1053- 1083.

[8] Chongvilaivan A., and J. Hur, 2012, Trade Openness and Vertical Integration: Evidence from the U.S. Manufacturing Sector, Southern Economic Journal, 78(4), 1242-1264.

[9] COM, 2010, EC Communication "Regional Policy for smart growth in Europe 2020".

[10] COM, 2011, Regional Policy contributing to sustainable growth in Europe 2020.

[11] Conconi, O., Legros, P. and A. Newman, 2012, Trade liberalization and organizational change, Journal of International Economics 86: 197-208.

[12] Dembour, C. , 2008, Competition for Business Location: A Survey, J Ind Compet Trade 8:89111.

[13] EU, 2012, Guide to Research and Innovation Strategies for Smart Specialization (RIS 3); Luxembourg: Publications Office of the European Union.

[14] Falck, O., Heblich, S., Kipar, S., 2010. Industrial innovation: Direct evidence from a cluster oriented policy. Regional Science and Urban Economics, 40 (6): 574-582.

[15] Grossman, G. M. and E. Helpman 2002. Integration versus Outsourcing in Industry Equilibrium, The Quarterly Journal of Economics, Vol. 117, No. 1, pp. 85-120.

[16] Helpman, E. , 2006, Trade, FDI, and the Organization of Firms, Journal of Economic Literature, Vol. XLIV, pp. 589-630.

[17] Iammarino, S. and Santangelo, G. D. (2000) Foreign direct investment and regional attractiveness in the EU integration process: some evidence for the Italian regions European Urban and Regional Studies, 7 (1). 5-18.

[18] Isaksen A and Onsager K (2010) Regions, networks and innovative performance: The case of knowledge-intensive industries in Norway. European Urban and Regional Studies 17: 227243.

[19] Legros, P. and A. F. Newman, 2014, Contracts, Ownership, and Industrial Organization: Past and Future forthcoming in Journal of Law, Economics and Organization. 
[20] Levchenko, A., 2007, Institutional Quality and International Trade, Review of Economic Studies.

[21] Macchiavello (2012), Financial development and Vertical integration: Theory and Evidence, Journal of European Economic Association, forthcoming.

[22] Martins, L. and J. M. Rodriguez Alvarez, 2007, Towards glocal leadership: taking up the challenge of new local governance in Europe? Environment and Planning C: Government and Policy 2007, volume 25, 391-409.

[23] Matsushima, N. ,2004, Technology of upstream firms and equilibrium product differentiation, International Journal of Industrial Organization 22 1091-1114.

[24] McLaren, J., 2000, Globalization and Vertical Structure, American Economic Review 90, 12391254.

[25] McLaren, J., 2003, Trade and market thickness: effects on organization, Journal of the European Economic Association, 1:328-336.

[26] Nishimura, J., Okamuro, H. , 2011. R\&D productivity and the organization of cluster policy: An empirical evaluation of the Industrial Cluster Project in Japan. The Journal of Technology Transfer, 36 (2): 117-144.

[27] Norman, G., Thisse, J.-F., 1999. Technology choice and market structure: strategic aspect of flexible manufacturing. Journal of Industrial Economics 47, 345-372.

[28] Nunn, N. , 2007. Relationship-Specificity, Incomplete Contracts, and Pattern of Trade, The Quarterly Journal of Economics.

[29] OECD , 2011. Reviews of Regional Innovation: Regions and Innovation Policy.

[30] OECD (2013), Regions and Innovation: Collaborating across Borders, OECD Reviews of Regional Innovation, OECD Publishing.

[31] Ornelas, E. and J. L. Turner , 2008, Trade liberalization, outsourcing, and the hold-up problem, Journal of International Economics 74, 225 - 241.

[32] Pascali, L., 2013, Determinants of Vertical Integration: Trade Policy, Contracts and Technology, mimeo.

[33] Rey, P. and J. Tirole, 2007, A Primer on Foreclosure, in M. Armstrong and Porter, R.(eds.),Handbook of Industrial Organization, vol.3, pp. 2145-2220, Elsevier, Amsterdam. 


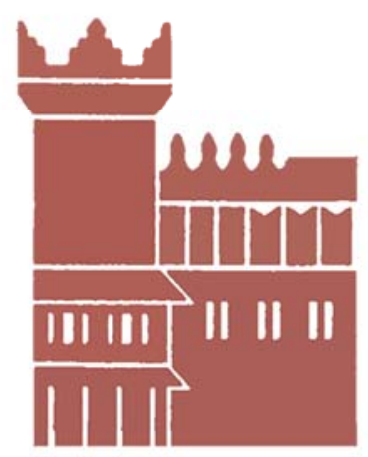

Alma Mater Studiorum - Università di Bologna DEPARTMENT OF ECONOMICS

Strada Maggiore 45

40125 Bologna - Italy

Tel. +39051 2092604

Fax +390512092664

http://www.dse.unibo.it 